\title{
Electrochemical Formation of Palladium Islands on HOPG: Kinetics, Morphology, and Growth Mechanisms
}

\author{
Y. Gimeno,${ }^{\dagger}$ A. Hernández Creus,${ }^{\dagger}$ P. Carro,${ }^{\dagger}$ S. González, ${ }^{\dagger}$ R. C. Salvarezza, ${ }^{\ddagger}$ and \\ A. J. Arvia**: \\ Departamento de Química Física, Universidad de La Laguna, La Laguna, Tenerife, Spain, and \\ Instituto de Investigaciones Fisicoquímicas Teóricas y Aplicadas (INIFTA), Sucursal 4, \\ Casilla de Correo 16 (1900) La Plata, Argentina \\ Received: November 14, 2001
}

\begin{abstract}
Scanning tunneling microscopy (STM) and conventional electrochemical techniques were utilized to investigate the growth kinetics and mechanism of palladium island electroformation on highly oriented pyrolitic graphite (HOPG) from aqueous acid palladium chloride solutions at $298 \mathrm{~K}$. Initially, the electrodeposition reaction at low cathodic overpotentials involves an activation process in which a $\mathrm{PdCl}_{2}$ surface intermediate is formed. At intermediate overpotentials, the growth of palladium islands involves a progressive nucleation and growth model under diffusion control, whereas at high overpotentials, the bulk discharge of soluble palladium species undergoes a free convective-diffusion process. As the cathodic overpotential is shifted negatively, the aspect ratio of the islands, defined as the ratio of the maximum height of the island to the island radius, and the island size decrease, whereas the island density increases. As the cathodic overpotential becomes a few millivolts more positive than the threshold potential of the hydrogen evolution reaction, the island shape changes from a compact disk to a quasi-2D dense radial $\mathrm{Pd}(111)$ island. The formation of a dense radial morphology and its small departure from a perfect 2D pattern indicates the presence of weak step-edge energy barriers, as expected from theoretical calculations for $\mathrm{Pd}(111)$. These results stress the key role of step-edge energy barriers in determining growth patterns during metal electrodeposition.
\end{abstract}

\section{Introduction}

Solid-phase pattern formation and selection under nonequilibrium homoepitaxial or heteroepitaxial growth has been an intriguing field for a long time and has recently received considerable attention from both the theoretical and experimental standpoints. ${ }^{1-3}$ These studies have established the boundary conditions that determine whether a growth front becomes either stable or unstable, as well as the degrees of disorder that can be obtained at the different scales that are characteristic of growth patterns. ${ }^{1-3}$ These are fundamental issues in understanding a large number of natural phenomena, such as viscous fingering, dielectric breakdown, crystallization, electrocrystallization, and growth of bacterial colonies, as well as for the development of novel materials.

The growth of a solid phase can occur under two extreme kinetic situations, i.e., conditions either very close to or far from equilibrium. In the former case, classical growth models provide a reasonable framework for describing the growth kinetics, ${ }^{2}$ whereas, for the latter, concepts from nonequilibrium thermodynamics and statistical physics are required to approach a rationale of the kinetics of fast solid-phase growth.

Phase growth out of equilibrium is still a poorly understood topic, and its comprehensive theoretical understanding is also lacking, except for the diffusion-limited aggregation (DLA) model, ${ }^{1}$ which accounts, at the phenomenological level, for the formation of many patterns in which the typical fractal structure of aggregates arises from the tip instability leading to splitting.

\footnotetext{
* To whom correspondence should be addressed.

† Universidad de La Laguna.

Instituto de Investigaciones Fisicoquímicas Teóricas y Aplicadas (INIFTA).
}

Metal electrodeposition appears to be a process that can be investigated to elucidate the role played by both local and nonlocal effects in the growth of solid phases, particularly in determining the morphologies of deposits. ${ }^{1,2,4}$ In these cases, by changing the applied potential, it is possible to change from quasi-equilibrium to nonequilibrium growth conditions. For the latter, depending on whether the growth process is dominated by local or nonlocal effects, either a compact self-affine or an open self-similar fractal deposit can be produced. ${ }^{1,3,4}$ However, the complex growth patterns resulting in experimental systems seem to indicate that, in many cases, both effects contribute nonuniformly along the reaction front during the growth process, causing alternating morphology transitions between dendrites and a dense radial morphology. ${ }^{5-7}$ Therefore, the selection rule in pattern formation results in a complex issue for which a comprehensive description is still lacking.

In contrast to vapor deposition, little is known about the role of energy barriers that affect the rate of displacement of atoms on metal surfaces and how these energy barriers determine pattern formation in metal electrodeposition. However, we have recently found that electrodeposited nanometer-sized gold islands on highly oriented pyrolytic graphite (HOPG) grown under mass transport control exhibit a transition from hemispherical euclidean to dendritic morphology as the electrodeposition potential $(E)$ is moved in the negative direction. ${ }^{5,6}$ This transition was explained in terms of an applied-potentialdependent change in the energy barrier for gold adatom surface diffusion at step edges. Thus, the initially isotropic surface diffusion turns into an anisotropic surface diffusion process that stabilizes tip growth by surface diffusion of gold adatoms in preferred step directions. The applied-potential-dependent transition occurs in the neighborhood of the potential of zero charge 
of gold in the aqueous electrolyte solution and has been related to the influence of chloride ion adsorption on gold electrodeposition. The departure from 2D patterns observed for dendritic islands was also a sign of the presence of step-edge energy barriers for gold atom surface diffusion. In contrast to gold, theoretical calculations have shown that palladium has weak step-edge energy barriers. ${ }^{8}$ Therefore, palladium was chosen to test the influence of step-edge energy barriers on the growth pattern morphology.

The manageability of the pattern morphology of palladium aggregates is critical in dealing with palladium catalysts. The catalytic effect of powered palladium on redox reactions has been well-known for a long time. ${ }^{9,10}$ Likewise, disperse palladium is a unique catalyst for hydrogenation processes, as the adsorption properties and catalytic effect of this material depend on the texture of the palladium deposits and, in turn, on the deposition potential. ${ }^{15-18}$ In fact, very recently, solid palladium nanoparticles were used as a catalyst for the oxidation of substituted $p$-phenyl diamines by an amine-chloride-containing cobalt complex in heptane microemulsions, ${ }^{19}$ and palladium was chosen as a material for nanoscale interdigitated electrodes because it is easily modified for the attachment of biomolecules for biosensor applications. ${ }^{20}$

This work addresses the kinetics and mechanism of the electrodeposition of palladium islands on HOPG from an aqueous acidic palladium chloride solution containing an excess of sodium perchlorate in relation to the island topography and aspect ratio. The early stages of palladium electrodeposition is well described by a nucleation and 3D growth model under mass transport control. As the cathodic potential is negatively increased, the island size decreases, the island density increases, and the island shape changes from hemispherical to dense radial, just a few millivolts more positive than the threshold potential of the hydrogen evolution reaction. The small departure from perfect 2D islands and the development of a dense radial pattern indicates the presence of weak step-edge energy barriers, in agreement with the theoretical calculations. Results presented in this work stress the key role of step-edge energy barriers in determining growth patterns in metal electrodeposition. They also allowed us to establish that the location of the applied cathodic potential with respect to the potential of zero charge of bulk palladium plays a critical role in determining the aspect ratio of palladium islands.

\section{Experimental Section}

Palladium islands were electrodeposited onto a freshly exfoliated HOPG working electrode (geometric area $0.55 \mathrm{~cm}^{2}$ ) from aqueous $7.5 \times 10^{-4} \mathrm{M}$ palladium chloride $+5 \times 10^{-2} \mathrm{M}$ sodium perchlorate $+5 \times 10^{-3} \mathrm{M}$ perchloric acid (working solution) utilizing a conventional glass electrochemical cell provided with a palladium counter electrode and a saturated calomel electrode (SCE) as the reference. Potentials in the text are referred to the SCE scale. Cathodic polarization curves were recorded at $5 \times 10^{-3} \mathrm{~V} / \mathrm{s}$ from 0.85 to $-0.35 \mathrm{~V}$, i.e., a potential exceeding the threshold potential of the hydrogen evolution reaction (HER) at $298 \mathrm{~K}$. These curves were plotted as current density $(j)$ referred to the geometrical area of the HOPG substrate versus applied potential $(E)$. To determine the kinetics of the cathodic process in different potential windows, voltammetric polarization curves were run at potential scanning rates in the range of $0.010 \mathrm{~V} / \mathrm{s}<v<0.200 \mathrm{~V} / \mathrm{s}$, and potentiostatic current transients were recorded in the potential range of 0.28 $\mathrm{V}<E_{\mathrm{d}}<0.40 \mathrm{~V}$.

The working solution was prepared from analytical-reagentgrade chemicals and MilliQ*-Millipore water and used after saturation with purified argon. To establish the influence of both the substrate and the chloride ion concentration on palladium island electrodeposition, comparable polarization curves utilizing both HOPG and bulk palladium electrodes were also recorded. These experiments were performed using the working solution either plain or with the addition of $6 \times 10^{-3} \mathrm{M}$ potassium chloride.

Palladium islands were grown by stepping the potential from $E_{i}=0.7 \mathrm{~V}$ to a value of $E_{\mathrm{d}}$ set in the range $-0.1 \mathrm{~V} \leq E_{\mathrm{d}} \leq 0.4$ $\mathrm{V}$. The electrodeposition time $(t)$ was in the range $10 \mathrm{~s} \leq t \leq$ $650 \mathrm{~s}$, and the electrodeposition charge density $\left(q_{\mathrm{d}}\right)$ was in the range $1 \mathrm{mC} \mathrm{cm}^{-2} \leq q_{\mathrm{d}} \leq 5 \mathrm{mC} \mathrm{cm}^{-2}$.

STM imaging proceeded after each HOPG working electrode partially covered by palladium was removed from the cell, rinsed by immersion in water for $2 \mathrm{~min}$, and finally dried under argon at room temperature. Subsequently, images were obtained using a Nanoscope IIE STM (Digital Instruments, Santa Barbara, CA) with $\mathrm{Pt}$ - Ir nanotips operating in air. Because of the stability of both palladium electrodeposits and HOPG in air, ex situ images of electrodeposits were obtained by setting the tunneling current in the range $0.5-0.8 \mathrm{nA}$ and the bias voltage in the range $0.5-$ $1.0 \mathrm{~V}$. To avoid either the damage of electrodeposited islands or their removal by the tip because of their rather poor adherence to HOPG, images were taken at a low scanning rate, usually on the order of $0.8 \mathrm{~Hz}$ for images $5 \times 5 \mu \mathrm{m}^{2}$ in size.

Occasionally, conventional scanning electron micrographs (SEM) were obtained, particularly to discard any possible tipinduced artifacts in the STM images.

\section{Results}

3.1. Polarization Curves. A cathodic polarization curve of HOPG in the working solution recorded from $0.85 \mathrm{~V}$ downward (Figure 1a) shows first a portion extending from 0.47 to 0.38 $\mathrm{V}$, followed by a first rapid increase in the cathodic current density $\left(j_{\mathrm{c}}\right)$ from 0.38 to $0.33 \mathrm{~V}$ that tends to attain a limiting current $\left(j_{\mathrm{L} 1} \approx 29 \mu \mathrm{A} / \mathrm{cm}^{2}\right)$. From $0.33 \mathrm{~V}$ downward, another fast increase in cathodic current up to a maximum at $0.28 \mathrm{~V}$, followed by a second limiting current $\left(j_{\mathrm{L} 1 \mathrm{I}} \approx 52 \mu \mathrm{A} / \mathrm{cm}^{2}\right)$ from about 0.10 to $-0.15 \mathrm{~V}$, is observed. Finally, for $-0.18 \mathrm{~V}$, a cathodic current hump is recorded, which is followed by a rapid increase in the cathodic current for $E<-0.3 \mathrm{~V}$ due to the hydrogen ion discharge reaction. The $E$ vs $\log j$ plot (Figure 1b), with a correction for HOPG double-layer charging, shows a first linear portion in the potential range of $0.47-0.38 \mathrm{~V}$ with a cathodic Tafel slope close to $-0.060 \mathrm{~V} /$ decade $\approx-2.303$ $(R T / F)$. This result suggests that the initial stage of palladium electrodeposition on HOPG is under activation control, in agreement with previously reported kinetic data. ${ }^{21,22}$ The appearance of limiting currents $j_{\mathrm{L} 1}$ and $j_{\mathrm{L} 1 \mathrm{I}}$ in Figure 1a indicates that, after the Tafel region, the cathodic process is under diffusion control. This is confirmed by voltammetry runs (Figure 2a) that show a linear increase in the height of the cathodic current peak $\left(j_{\mathrm{cp}}\right)$ with $v^{1 / 2}$ (Figure $2 \mathrm{~b}$ ).

The polarization curve depends on the concentration of chloride ions in the solution through ionic equilibria determining the ionic composition of the solution (Table 1). Thus, as the chloride ion concentration is increased (Figure 1c), both $j_{\mathrm{L} 1}$ and the current maximum preceding $j_{\mathrm{L} 1 \mathrm{I}}$ decrease, but $j_{\mathrm{L} 1 \mathrm{I}}$ is better defined. This behavior agrees with a displacement of ionic equilibria in solution toward reactants with a larger chlorine/ palladium atom ratio. Therefore, to understand the electrochemical reaction occurring at different ranges of potential, ionic equilibria involving palladium chloride complexes in the working solution have to be considered. 

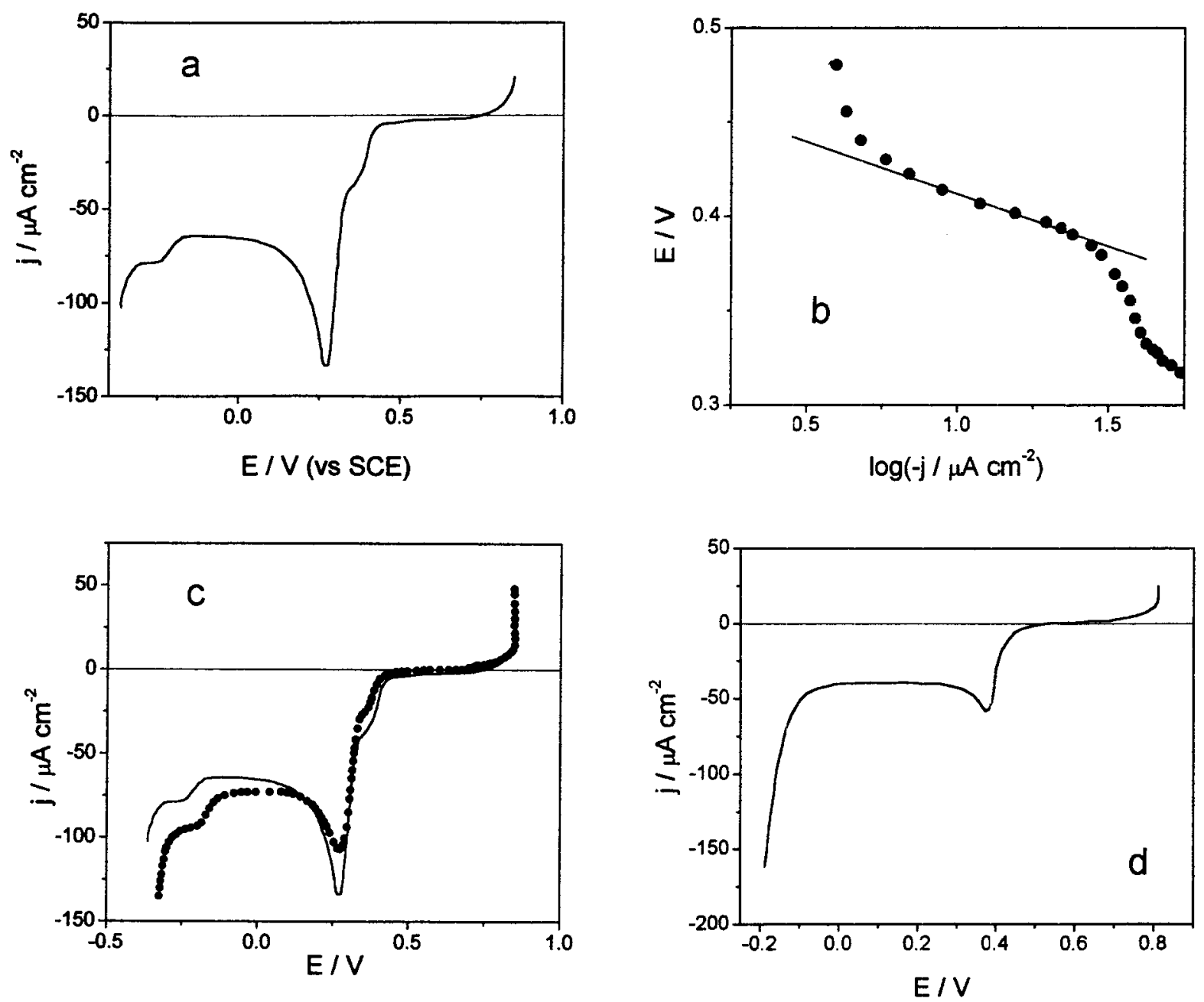

Figure 1. (a) Voltammogram of HOPG in aqueous $7.5 \times 10^{-4} \mathrm{M} \mathrm{PdCl}_{2}+5 \times 10^{-2} \mathrm{M} \mathrm{NaClO}_{4}+5 \times 10^{-3} \mathrm{M} \mathrm{HClO}_{4} ; v=5 \times 10^{-3} \mathrm{~V} / \mathrm{s} ; 298$ $\mathrm{K}$. The current density $(j)$ is referred to the working electrode geometric area. (b) $E$ vs $\log j$ plot. Data taken from Figure 1a. The straight line with slope $-2.303(R T / F)$ is indicated. (c) Voltammogram of bulk palladium in aqueous $7.5 \times 10^{-4} \mathrm{M} \mathrm{PdCl}_{2}+5 \times 10^{-2} \mathrm{M} \mathrm{NaClO}_{4}+5 \times 10^{-3} \mathrm{M}$ $\mathrm{HClO}_{4} ; v=5 \times 10^{-3} \mathrm{~V} / \mathrm{s} ; 298 \mathrm{~K}$. (d) Comparative voltammograms for $\mathrm{HOPG}$ in aqueous $7.5 \times 10^{-4} \mathrm{M} \mathrm{PdCl}_{2}+5 \times 10^{-2} \mathrm{M} \mathrm{NaClO}_{4}+5 \times 10^{-3}$ $\mathrm{M} \mathrm{HClO}_{4}$ (full trace) and aqueous $7.5 \times 10^{-4} \mathrm{M} \mathrm{PdCl}_{2}+5 \times 10^{-2} \mathrm{M} \mathrm{NaClO}_{4}+5 \times 10^{-3} \mathrm{M} \mathrm{HClO}_{4}+6 \times 10^{-3} \mathrm{M} \mathrm{KCl}($ dotted trace); $v=$ $5 \times 10^{-3} \mathrm{~V} / \mathrm{s} ; 298 \mathrm{~K}$.

To determine the soluble palladium species involved in the electrodeposition process, the stability constants $(\beta)$, the standard electrode potential at $298 \mathrm{~K}\left(E^{\circ}\right)$, the equilibrium concentration $\left(c_{i}\right)$, and the reversible potential $(E)$ of each complex species should be considered (Table 1). Thermodynamic data ${ }^{23,24}$ indicate that for $E<0.528 \mathrm{~V}$, the discharge of $\mathrm{Pd}^{2+}$ and $\mathrm{PdCl}^{+}$ species is favored, whereas for $E<0.50 \mathrm{~V}$, all soluble palladium species can be electroreduced. Accordingly, for $E<0.53 \mathrm{~V}$, reactions such as

$$
\mathrm{Pd}^{2+}+2 \mathrm{e}^{-}=\mathrm{Pd} \quad E_{\mathrm{r}}=0.526 \mathrm{~V}
$$

and

$$
\mathrm{PdCl}^{+}+2 \mathrm{e}^{-}=\mathrm{Pd}+\mathrm{Cl}^{-} \quad E_{\mathrm{r}}=0.528 \mathrm{~V}
$$

can be considered as the main reactions related to $j_{\mathrm{L} 1}$. Similarly, for $E<0.50 \mathrm{~V}$, the reactions

$$
\mathrm{PdCl}_{2}+2 \mathrm{e}^{-}=\mathrm{Pd}+2 \mathrm{Cl}^{-} \quad E_{\mathrm{r}}=0.491 \mathrm{~V}
$$

and

$$
\mathrm{PdCl}_{3}^{-}+2 \mathrm{e}^{-}=\mathrm{Pd}+3 \mathrm{Cl}^{-} \quad E_{\mathrm{r}}=0.493 \mathrm{~V}
$$

together with reactions 1 and 2 should contribute to $j_{\text {LII }}$.
At high negative values of $E$, the convective-diffusion limiting current in stagnant solution is given by the expression ${ }^{25}$

$$
j_{\mathrm{L}}={ }_{z} F D_{i} c_{i} / \delta_{N}
$$

where $z$ is the number of electrons transferred per reacting species, $c_{i}$ is the concentration of reacting species, $D_{i}$ is the average diffusion coefficient of reacting species in the electrolyte solution, $\delta_{N}$ is the average thickness of the diffusion layer for the quiescent solution, and the Faraday constant $F=96500$ $\mathrm{C} / \mathrm{mol}$. From eq 5, taking $c_{i}=4.2 \times 10^{-7} \mathrm{~mol} / \mathrm{cm}^{3}$ for the concentration of $\mathrm{PdCl}^{+}+\mathrm{Pd}^{2+}$ species, $c_{i}=3.32 \times 10^{-7} \mathrm{~mol} /$ $\mathrm{cm}^{3}$ for the concentration of $\mathrm{PdCl}_{2}+\mathrm{PdCl}_{3}{ }^{-}$species, $z=2, D_{i}$ $=0.67 \times 10^{-5} \mathrm{~cm}^{2} / \mathrm{s},{ }^{26}$ and $\delta_{N}=0.02 \mathrm{~cm},{ }^{23}$ one obtains $j_{\mathrm{L} 1}=$ $29 \mu \mathrm{A} / \mathrm{cm}^{2}$ and $j_{\mathrm{LII}}=52 \mu \mathrm{A} / \mathrm{cm}^{2}$, so that $j_{\mathrm{L} 1 \mathrm{I}} / j_{\mathrm{LI}} \approx 1.8$ is in good agreement with the experimental value. Therefore, electrochemical data indicate that, for $E<0.475 \mathrm{~V}$, all soluble palladium species are discharged.

On the other hand, the cathodic polarization curve of a bulk palladium electrode in the working solution (Figure 1d) also starts at $0.528 \pm 0.005 \mathrm{~V}$, as expected from thermodynamic data (Table 1). Accordingly, the cathodic overpotential is defined as $\eta_{\mathrm{c}}=E-0.528 \mathrm{~V}$. In contrast to the polarization curve recorded on HOPG (Figure 1a), this curve exhibits a single 

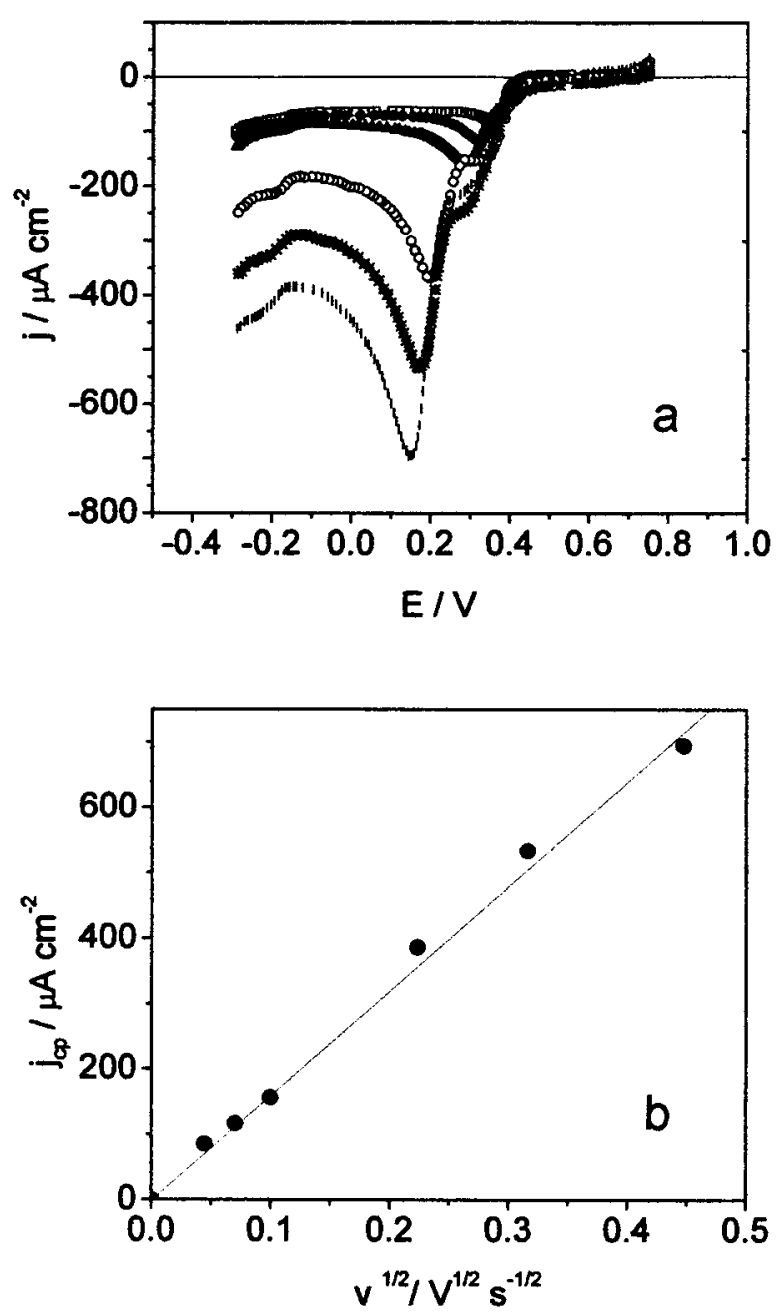

Figure 2. (a) Voltammograms obtained for $\mathrm{HOPG}$ in aqueous $7.5 \times$ $10^{-4} \mathrm{M} \mathrm{PdCl}_{2}+5 \times 10^{-2} \mathrm{M} \mathrm{NaClO}_{4}+5 \times 10^{-3} \mathrm{M} \mathrm{HClO}_{4}$ at different potential scan rates, $v=2 \mathrm{mV} / \mathrm{s}$ (top curve), $5 \mathrm{mV} / \mathrm{s}, 10 \mathrm{mV} / \mathrm{s}, 50$ $\mathrm{mV} / \mathrm{s}, 0.1 \mathrm{~V} / \mathrm{s}$, and $0.2 \mathrm{~V} / \mathrm{s}$ (bottom curve). $298 \mathrm{~K}$. (b) Plot of $j_{\mathrm{cp}} \mathrm{vs}$ $v^{1 / 2}$. Data taken from Figure 2a.

TABLE 1: Thermodynamic Data for Species Involved in the Electrodeposition Process

\begin{tabular}{|c|c|c|c|c|}
\hline species & $\log \beta$ & $E^{\circ}$ vs SCE (V) & $E_{\mathrm{r}}$ vs SCE (V) & $c_{i}(\mathrm{M})$ \\
\hline \multicolumn{5}{|c|}{$0.75 \mathrm{M} \mathrm{PdCl}_{2}+0.050 \mathrm{M} \mathrm{NaClO}_{4}+0.0050 \mathrm{M} \mathrm{HClO}_{4}$} \\
\hline $\mathrm{Cl}^{-}$ & & & & $4.13 \times 10^{-4}$ \\
\hline $\mathrm{Pd}^{2+}$ & & 0.709 & 0.526 & $3.16 \times 10^{-5}$ \\
\hline $\mathrm{PdCl}^{+}$ & 4.47 & 0.529 & 0.528 & $3.86 \times 10^{-4}$ \\
\hline $\mathrm{PdCl}_{2}$ & 7.74 & 0.396 & 0.4 & $2.97 \times 10^{-4}$ \\
\hline $\mathrm{PdCl}_{3}^{-}$ & 10.2 & 0.325 & 0.493 & $3.54 \times 10^{-5}$ \\
\hline $\mathrm{PdCl}_{4}{ }^{2-}$ & 11.5 & 0.349 & 0.640 & $2.92 \times 10^{-7}$ \\
\hline \multicolumn{5}{|c|}{$\begin{array}{c}0.75 \mathrm{M} \mathrm{PdCl}_{2}+0.050 \mathrm{M} \mathrm{NaClO}_{4}+0.0050 \mathrm{M} \mathrm{HClO}_{4}+ \\
\quad 6.0 \times 10^{-3} \mathrm{M} \mathrm{KCl}\end{array}$} \\
\hline $\mathrm{Cl}^{-}$ & & & & $5.52 \times 10^{-3}$ \\
\hline $\mathrm{Pd}^{2+}$ & & 0.709 & 0.508 & $1.56 \times 10^{-7}$ \\
\hline $\mathrm{PdCl}^{+}$ & 4.47 & & & $2.55>$ \\
\hline $\mathrm{PdCl}_{2}$ & 7.74 & 0.396 & 0.423 & $2.62 \times 10^{-4}$ \\
\hline $\mathrm{PdCl}_{3}^{-}$ & 10.2 & 0.325 & 0.425 & $4.17 \times 10^{-4}$ \\
\hline $\mathrm{PdCl}_{4}{ }^{2-}$ & 11.5 & 0.349 & 0.487 & $4.59 \times 10^{-5}$ \\
\hline
\end{tabular}

cathodic limiting current extending negatively from $0.4 \mathrm{~V}$, preceded by the same current maximum as observed for HOPG. This type of current maximum is usually found for diffusioncontrolled electrochemical reactions under a linear potential scan. Otherwise, in contrast to palladium electrodeposition on HOPG, no hump preceding the hydrogen ion discharge reaction on bulk palladium is observed. Therefore, the cathodic current hump at about $-0.18 \mathrm{~V}$, recorded only when palladium islands are already formed on HOPG, is consistent with a surface electrochemical reaction involving the simultaneous discharge of all reactants in solution, including hydrogen ions on previously formed palladium islands. Despite the complexity of the hydrogen ion discharge reaction on bulk palladium, ${ }^{27,28} \mathrm{com}$ prising hydrogen adsorption, hydrogen absorption, hydrogen alloy formation, and molecular hydrogen formation, it has been demonstrated that nanostructured palladium deposits exhibit an enhancement for hydrogen atom adsorption. ${ }^{29}$ This process appears to be responsible for the cathodic hump at $-0.18 \mathrm{~V}$. The height and charge of this hump (Figure 2a) depend on both $v$ and $q_{\mathrm{d}}$.

3.2. Potentiostatic Current Transients. The shape of potentiostatic current transients obtained by stepping the potential from 0.7 to $0.38 \mathrm{~V} \leq E_{\mathrm{d}} \leq-0.1 \mathrm{~V}$, i.e., running in the potential range where the electrodeposition reaction is under diffusion control (Figure 3a), depends on $E_{\mathrm{d}}$. Thus, for $E_{\mathrm{d}}=$ $0.365 \mathrm{~V}$, i.e., a potential lower than any equilibrium potential shown in Table 1, the current transient consists of the initial fast current decay because of the contribution of the doublelayer charging that is significant for $t<1 \mathrm{~s}$, followed first by a fast increase in current up to a maximum value $j_{\mathrm{M}}$ at time $t_{\mathrm{M}}$, followed by a slow decay. As $E_{\mathrm{d}}$ is set more negative, $j_{\mathrm{M}}$ increases, and $t_{\mathrm{M}}$ decreases, as is usually found for the nucleation of solid phases produced electrochemically. After a time $t_{\mathrm{c}}$ that depends on $E_{\mathrm{d}}$, the contribution of free convection sets in, and all transients approach the quasi-steady convective-diffusion regime characterized by $j_{\mathrm{LII}}$. Otherwise, for $E_{\mathrm{d}}<-0.200 \mathrm{~V}$, at the time scale of current transient plots, only the current decay is observed, and for $t<10 \mathrm{~s}$, current transients fit a $j$ vs $t^{-1 / 2}$ plot (Figure 3b), as expected for a pure-diffusion regime of reactants from the solution. Current data deviate from Fick's law for $t>10 \mathrm{~s}$, as the convective-diffusion regime is approached. Then, results indicate that the electroformation of palladium islands begins as a nucleation process under diffusion control followed by phase growth under convective diffusion.

From the best fit of the $j$ vs $t^{-1 / 2}$ data for $E_{\mathrm{d}}=-0.100 \mathrm{~V}$ and $t<10 \mathrm{~s}$ to Fick's law (Figure 3b), the average diffusion coefficient of the reactants was estimated from the equation

$$
j=z F D^{1 / 2} c_{i} / \pi^{1 / 2} t^{1 / 2}
$$

considering $z=2, \Delta j / \Delta t^{-1 / 2}=2.67 \times 10^{-6} \mathrm{As}^{1 / 2} / \mathrm{cm}^{2}, c_{i}=7$ $\times 10^{-7} \mathrm{~mol} / \mathrm{cm}^{3}$, and $F=96500 \mathrm{C} / \mathrm{mol}$. The resulting value $D_{i}=0.67 \times 10^{-5} \mathrm{~cm}^{2} / \mathrm{s}$ agrees with data that have been reported for comparable systems. ${ }^{26}$

3.3. Topography Description: SEM Micrographs and STM Imaging. Palladium islands produced from the same $q_{\mathrm{d}}$ in the different regions of the polarization curve show distinct morphologies. In general, the more rounded the islands are, the higher the value of $E_{\mathrm{d}}$ that results. Thus, electrodeposits grown at $E_{\mathrm{d}}=0.38 \mathrm{~V}$ from $q_{\mathrm{d}}=5 \mathrm{mC} / \mathrm{cm}^{2}$ consist of large rounded crystals with an average radius of $\langle r\rangle=200 \mathrm{~nm}$. The number density of these crystals determined from SEM micrographs (Figure 4) is $N_{\mathrm{c}}=4 \times 10^{7} \mathrm{~cm}^{-2}$. These crystals are easily removed by the STM tip because of their poor adherence to HOPG.

STM images of palladium islands made for $E_{\mathrm{d}}=0.125 \mathrm{~V}$ and $q_{\mathrm{d}}=1.2 \mathrm{mC} / \mathrm{cm}^{2}$ (Figure 5a) approach the shape of compact rounded disks appearing either randomly distributed or decorating HOPG steps. These islands form dimers, trimers, and chains of islands for $q_{\mathrm{d}}=3 \mathrm{mC} / \mathrm{cm}^{2}$ (Figure $5 \mathrm{~b}$ ). The average radius of these islands derived from the STM image cross sections is $\langle r\rangle=70 \mathrm{~nm}$, and the average height is $\langle h\rangle=35 \mathrm{~nm}$ (Figure $5 c)$. The average number density of islands resulting from STM 

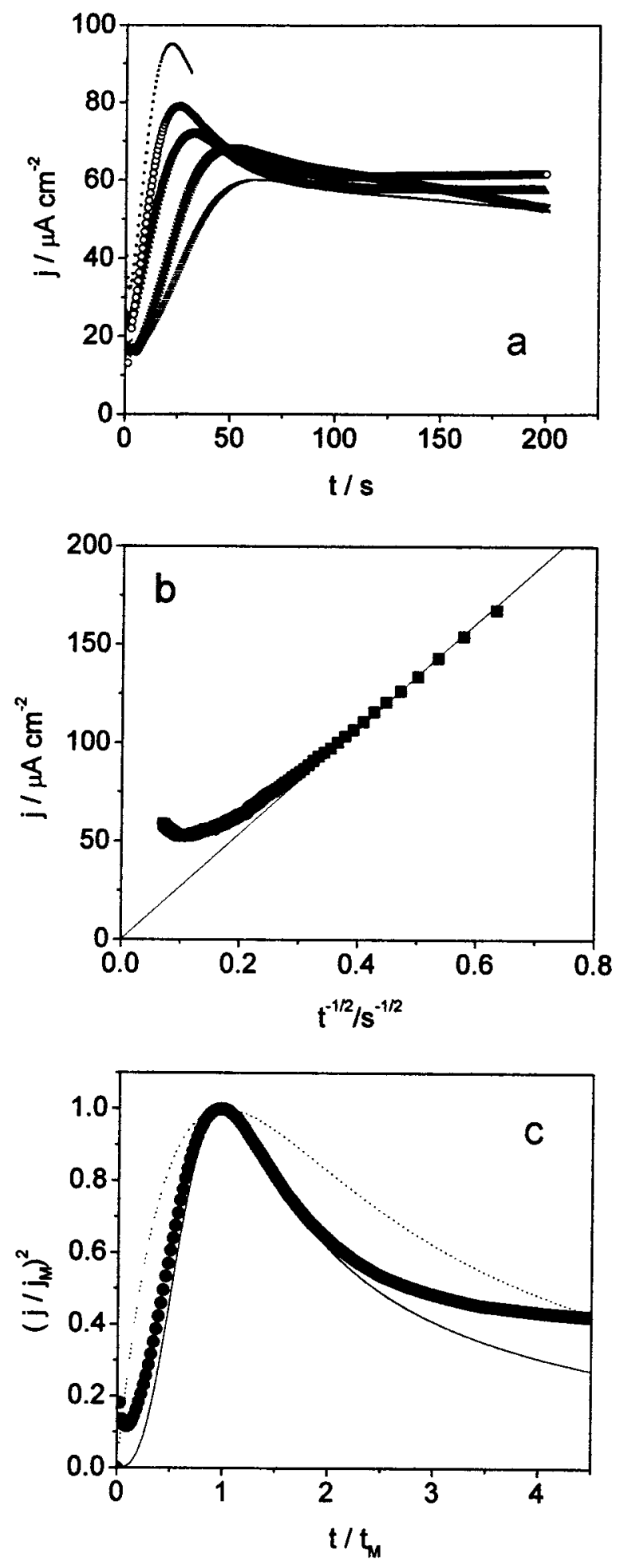

Figure 3. (a) Typical potentiostatic current transients run from $E_{\mathrm{d}}=$ $0.355 \mathrm{~V}$ (top) to $E_{\mathrm{d}}=0.390 \mathrm{~V}$ (bottom). (b) $j$ vs $t^{-1 / 2}$ plot from the current transient run at $E_{\mathrm{d}}=-0.100 \mathrm{~V}$. The straight line corresponds to Fick's equation for linear diffusion. (c) Comparison of current transient data for $E_{\mathrm{d}}=0.355 \mathrm{~V}$ to those predicted by the instantaneous (dashed trace) and progressive (continuous trace) nucleation models under diffusion control. ${ }^{33}$

images and SEM micrographs is $N=3.6 \times 10^{8} \mathrm{~cm}^{-2}$ for $q_{\mathrm{d}}=$ $3 \mathrm{mC} \mathrm{cm}^{-2}$. Under the above conditions, STM images (Figure $5 \mathrm{a}, \mathrm{c})$ already start to show the presence of instabilities at island edges. The agreement between STM images and SEM micrographs allowed us to discard any possible tip-induced artifacts in our STM images.

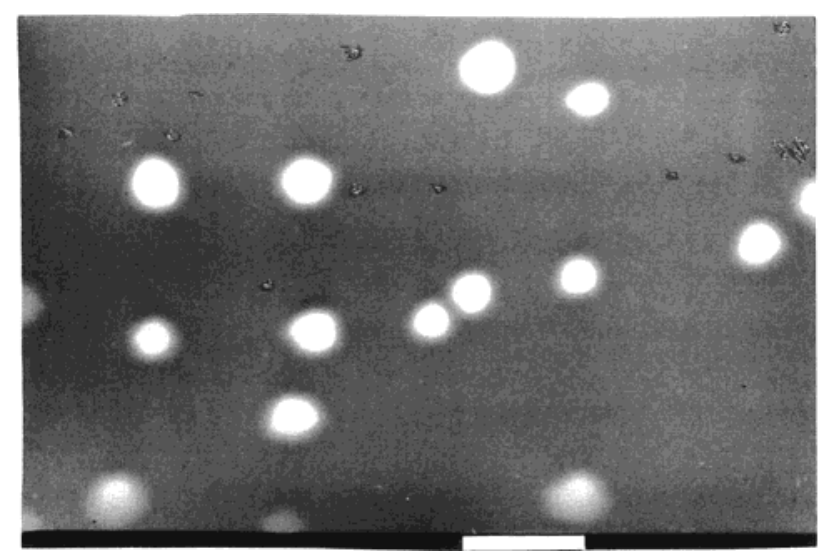

Figure 4. SEM micrograph (bar $=1 \mu \mathrm{m}$ ) of compact rounded palladium islands on HOPG; $E_{\mathrm{d}}=0.380 \mathrm{~V}, q_{\mathrm{d}}=5 \mathrm{mC} / \mathrm{cm}^{2}$.

Branched palladium islands on HOPG are obtained by setting $E_{\mathrm{d}}$ in the potential range of $j_{\mathrm{LII}}$ just preceding the HER threshold potential. The growth of these islands at $E_{\mathrm{d}}=-0.100 \mathrm{~V}$ was followed by sequential STM imaging for different values of $q_{\mathrm{d}}$. Thus, for $q_{\mathrm{d}}=1 \mathrm{mC} / \mathrm{cm}^{2}$ (Figure 6a), irregular islands either randomly distributed over the HOPG terraces or aligned and coming into contact with neighboring islands decorating HOPG steps can be observed, and in this case, $25 \mathrm{~nm} \leq\langle r\rangle \leq 35 \mathrm{~nm}$. Higher-resolution STM images (Figure 6b) show that each island consists of an agglomeration of small quasi-spheres $10-15 \mathrm{~nm}$ in size forming a quasi-spherical core. Giant clusters resulting from the mesoscale self-assembly of palladium nanocrystals 2.5 $\mathrm{nm}$ in diameter have been identified by transmission electron microscopy. ${ }^{30}$

As the charge passed is increased to $q_{\mathrm{d}}=1.5 \mathrm{mC} / \mathrm{cm}^{2}$, instabilities at island edges can already be seen (Figure 6c). The analysis of cross sections allowed us to establish a clear distinction between 3D and 2D growing areas of the electrodeposit and the tendency to develop a triangularly shaped island base in contact with HOPG. Large triangular clusters with preferential orientation have been grown on HOPG by vapor deposition at room temperature. ${ }^{31,32}$ Particularly in $2 \mathrm{D}$ growing areas, a number of instabilities appearing in the image as small protrusions can also be observed. For $q_{\mathrm{d}}=3 \mathrm{mC} / \mathrm{cm}^{2}$ (Figure $6 \mathrm{~d})$, the island number density increases, and each rounded island produces a net 3D core surrounded by a triangularly shaped 2D electrodeposit. In this case, $\langle r\rangle$ increases to $73 \mathrm{~nm}$. A detailed image of one of these islands (Figure 6e) shows a small central 3D core $20 \mathrm{~nm}$ in height. This height is almost the same as that of the initially formed rounded islands, surrounded by $2 \mathrm{D}$ branches, most of which merge at $120^{\circ}$ from the central core, resulting in a triangular island that is consistent with a (111) metallic lattice. As has recently been reported, ${ }^{31,32}$ STM images of palladium triangular islands on HOPG produced from the vapor phase demonstrate that, for every stage before and after heating and at all coverages, the local growth orientation is epitaxial fcc(111). For $q_{\mathrm{d}}=4 \mathrm{mC} / \mathrm{cm}^{2}$ (Figure $6 \mathrm{~g})$, the increase in $N$ and island size $(\langle r\rangle=81 \mathrm{~nm})$ leads to the partial overlap of neighboring branched centers. Secondary branches, separated by thin "fjords" $10 \mathrm{~nm}$ in width emerging from each main branch, tend to produce a dense growth pattern. These patterns closely resemble the dense radial morphologies that have been observed for several metallic electrodeposits exhibiting a nonfractal mass and a self-affine fractal perimeter. ${ }^{4}$

The island cross section taken from the core border to the tip of a main branch (Figure 6f) approaches the profile of a 2D pattern, revealing the formation of almost atomically smooth 

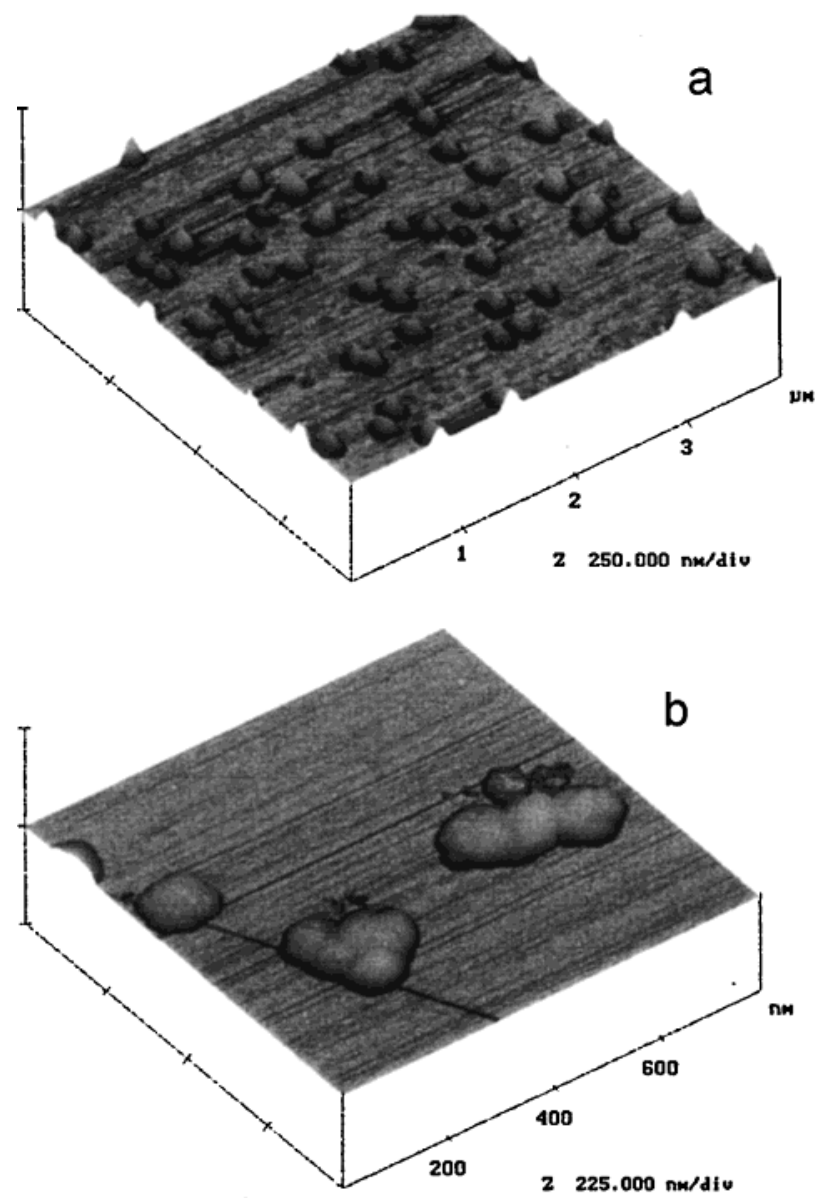

$\S^{n m}$
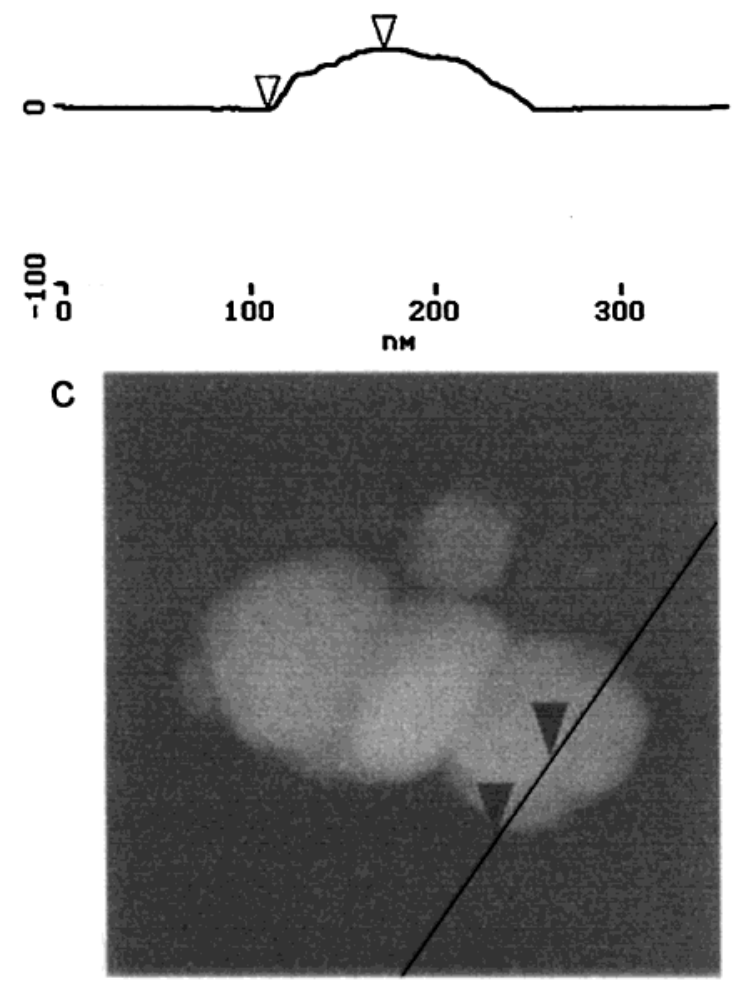

Figure 5. STM images of compact rounded palladium islands on HOPG; $E_{\mathrm{d}}=0.125 \mathrm{~V}$. (a) $0.8 \times 0.8 \mu \mathrm{m}^{2}, q_{\mathrm{d}}=1.2 \mathrm{mC} / \mathrm{cm}^{2}$. (b) 3.75 $\times 3.75 \mu \mathrm{m}^{2}, q_{\mathrm{d}}=3 \mathrm{mC} / \mathrm{cm}^{2}$. (c) Zoomed image $\left(0.4 \times 0.4 \mu \mathrm{m}^{2}\right)$ showing an island trimer and the cross section of an island. terraces. The height of each main branch decreases by only about $5 \mathrm{~nm}$ in going from the core border to the branch tip with an average slope close to $3-4^{\circ}$. These tapering effects of main branches mostly involve steps that are one atom high. Typical branch tip radii are close to $10 \mathrm{~nm}$, whereas the tip height fluctuates between 2 and $4 \mathrm{~nm}$.

3.4. Kinetic Data Obtained from Potentiostatic Current Transients and STM Images. To compare the behavior of current transients for $t<t_{\mathrm{c}}$ to the predictions of nucleation and growth models, experimental data were corrected for the doublelayer charging for $t<t_{\mathrm{M}}$. This correction was estimated from current transient data obtained for HOPG in palladium solutefree working solution and using the equation for the inflow of charge $q_{\mathrm{DL}}$ to the double-layer capacitance $C_{\mathrm{DL}}$, which, for $t \rightarrow$ 0 , is $\mathrm{d} q_{\mathrm{DL}}=C_{\mathrm{DL}} \mathrm{d} \Delta E=j \mathrm{~d} t$. Deconvoluted current transients fit the equation of progressive nucleation and $3 \mathrm{D}$ growth model under diffusion control ${ }^{33,34}$ (Figure 3c)

$$
j=\left(z F c_{i} D_{i}^{1 / 2} / \pi^{1 / 2} t^{1 / 2}\right)\left[1-\exp \left(-\pi K_{\mathrm{e}} D_{i} N_{\mathrm{o}} A_{\mathrm{c}} t^{2} / 2\right)\right]
$$

where $N_{\mathrm{o}}$ is the number of sites available for nucleation on the HOPG substrate and $A_{\mathrm{c}}$ is the frequency related to the conversion of a site into a nucleus. Equation 7 is obeyed in the region of the current maximum. At relatively long times data deviate from eq 7 because of the influence of free convection.

For $t_{\mathrm{M}}<t<t_{\mathrm{c}}$, the validity of Fick's law for simple linear diffusion for those current transients in the range $-0.1<E_{\mathrm{d}}<$ $0.40 \mathrm{~V}$ (Figure $3 \mathrm{~b}$ ) indicates that the diffusion zones built around each growing nucleus overlap, ${ }^{34}$ and the average size of the palladium nuclei is smaller than the nonstationary average thickness of the Nernst diffusion layer. Then, as growing nuclei are embedded in the diffusion layer thickness, no dependence of the value of $j$ on the increasing area of nuclei is observed. Finally, for $t>t_{\mathrm{c}}$, a quasi-stationary nucleus growth is approached because of the contribution of free convection. Under this condition, a constant value of $\delta_{N}$ is attained, irrespective of $E_{\mathrm{d}}$.

From STM images at constant $E_{\mathrm{d}}$, the increase in $q_{\mathrm{d}}$ results in the increase of both $N$ and $\langle r\rangle$. In fact, the $N$ vs $t$ plot (Figure 7a) exhibits an initially rapid increase in $N$ that later reaches a constant value. In the range $-0.10 \mathrm{~V} \leq E_{\mathrm{d}} \leq 0.15 \mathrm{~V}$, the time dependences of $\langle r\rangle$ and $\langle h\rangle$ are given by $\langle r\rangle \propto t^{n}$ with $n=0.4$ (Figure $7 \mathrm{~b}$ ) and $\langle h\rangle \propto t^{m}$ with $m=0.15$ (Figure 7c), respectively. These relationships indicate a preference for $2 \mathrm{D}$ over $3 \mathrm{D}$ growth as $q_{\mathrm{d}}$ is increased.

Values of the nucleation rate $A_{\mathrm{c}} N_{\mathrm{o}}$ were derived from an analysis of current transient maxima recorded at relatively low values of $\eta_{\mathrm{c}}=E_{\mathrm{d}}-E_{\mathrm{r}}{ }^{34}$ However, as current maxima at high $\eta_{\mathrm{c}}$ could not be observed in the time scale of current transients, in this case, values of $A_{\mathrm{c}} N_{\mathrm{o}}$ were obtained by fitting the $N$ vs $t$ plot (Figure 7a) with the following equation: ${ }^{35}$

$$
N=N_{\mathrm{o}}\left[1-\exp \left(-A_{\mathrm{c}} t\right)\right]
$$

Then, for $E_{\mathrm{d}}=-0.10 \mathrm{~V}$, one obtains $N_{\mathrm{o}}=4.0 \pm 0.5 \times 10^{9} /$ $\mathrm{cm}^{2}$ and $A_{\mathrm{c}}=0.33 \mathrm{~s}^{-1}$. In the range $-0.10 \mathrm{~V}<E_{\mathrm{d}}<0.365 \mathrm{~V}$, the values of $A_{\mathrm{c}} N_{\mathrm{o}}$ fulfill the equation (Figure $7 \mathrm{~d}$ )

$$
A N_{\mathrm{o}}=K_{1} \exp \left(-K_{2} / \eta_{\mathrm{c}}^{2}\right)
$$

where the constant $K_{1}$ depends on the nucleation dimension (2D, 3D) and mechanism (either diffusion or charge-transfer control) and the constant $K_{2}$ is related to $A_{\mathrm{c}}$ by ${ }^{34,35}$

$$
K_{2} / \eta_{\mathrm{c}}{ }^{2}=A_{\mathrm{c}} / k T
$$


a

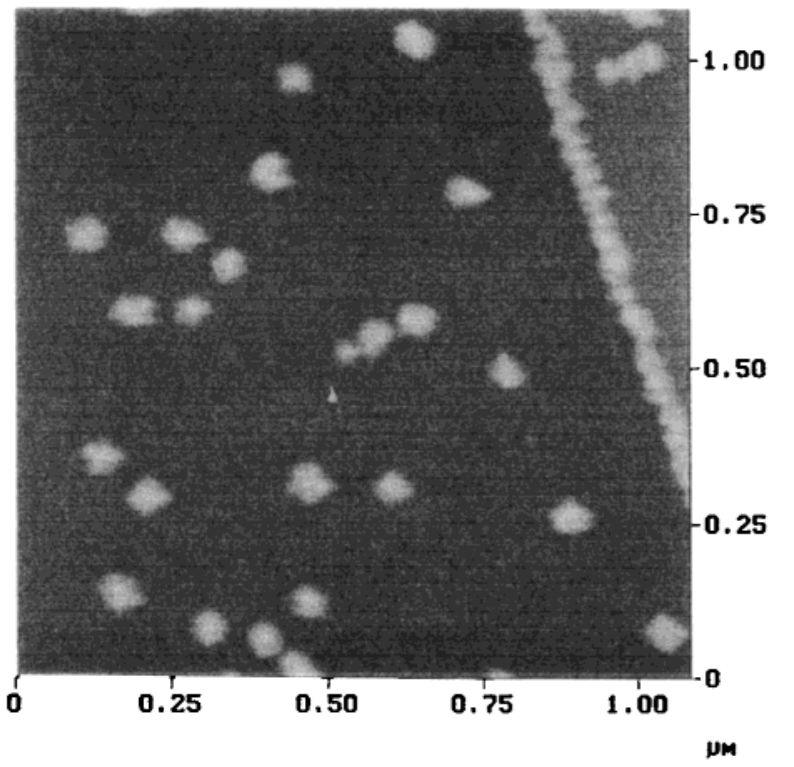

b

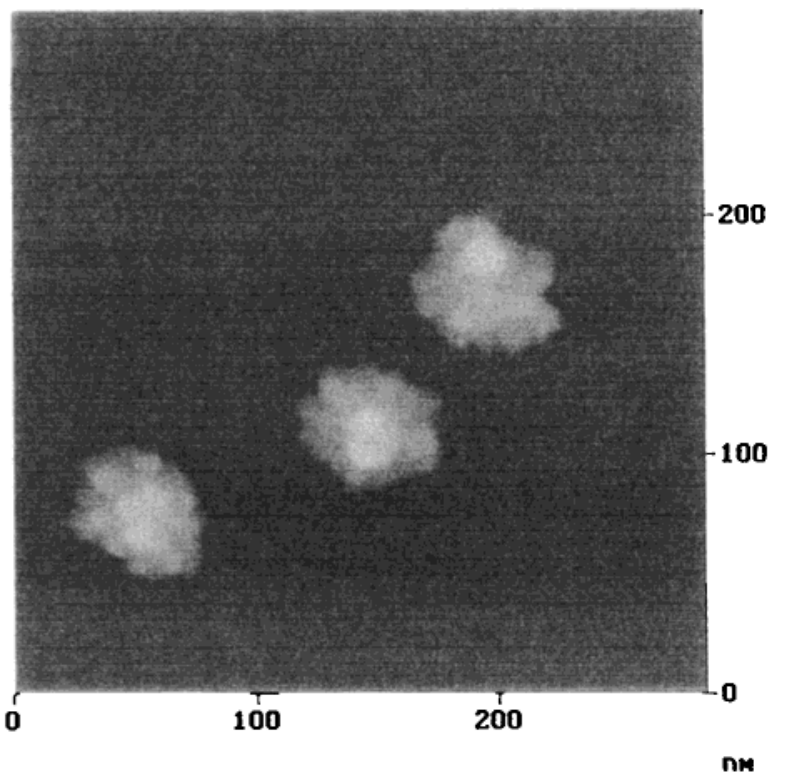

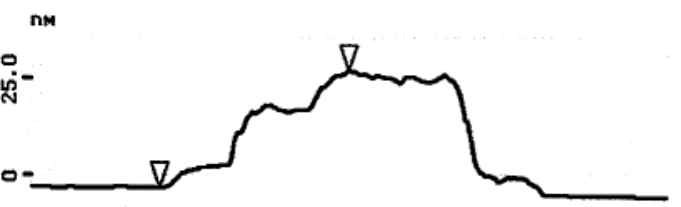

实-

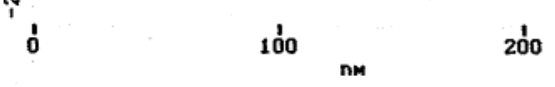

C

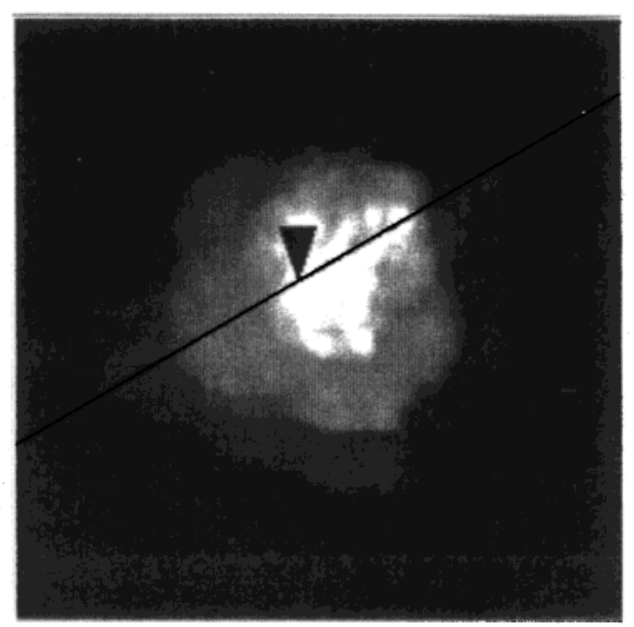

d

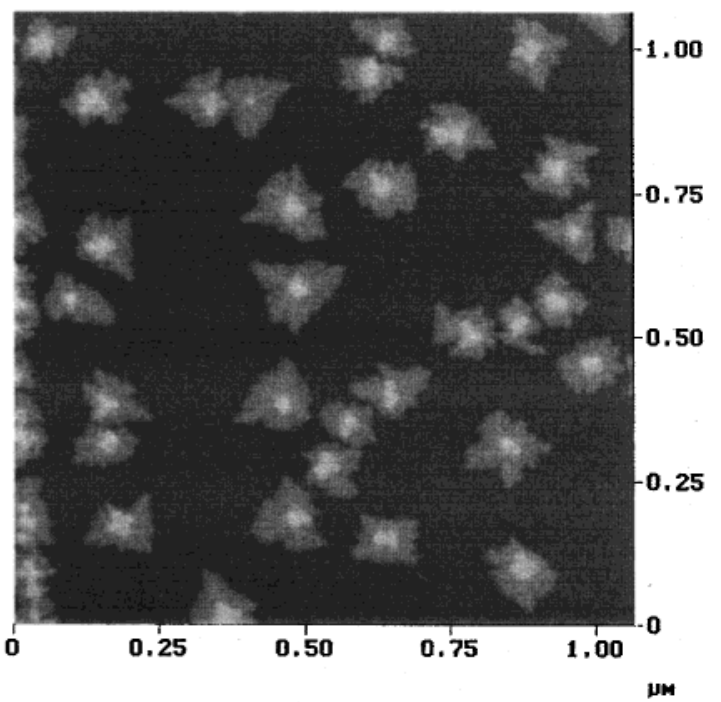

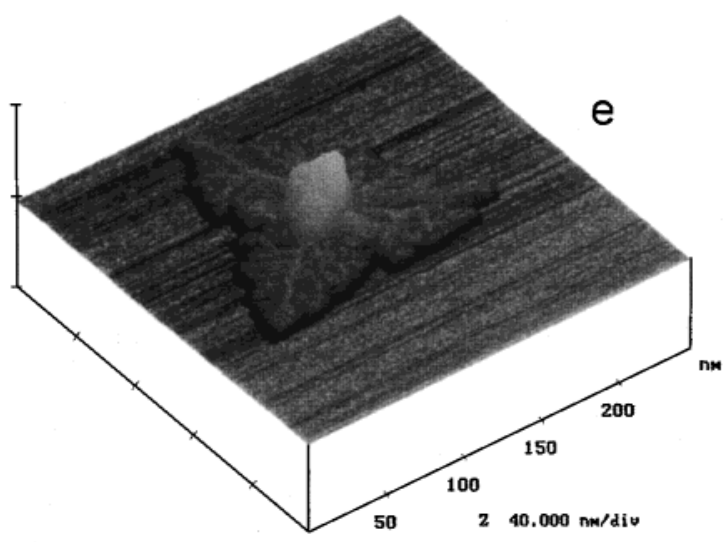



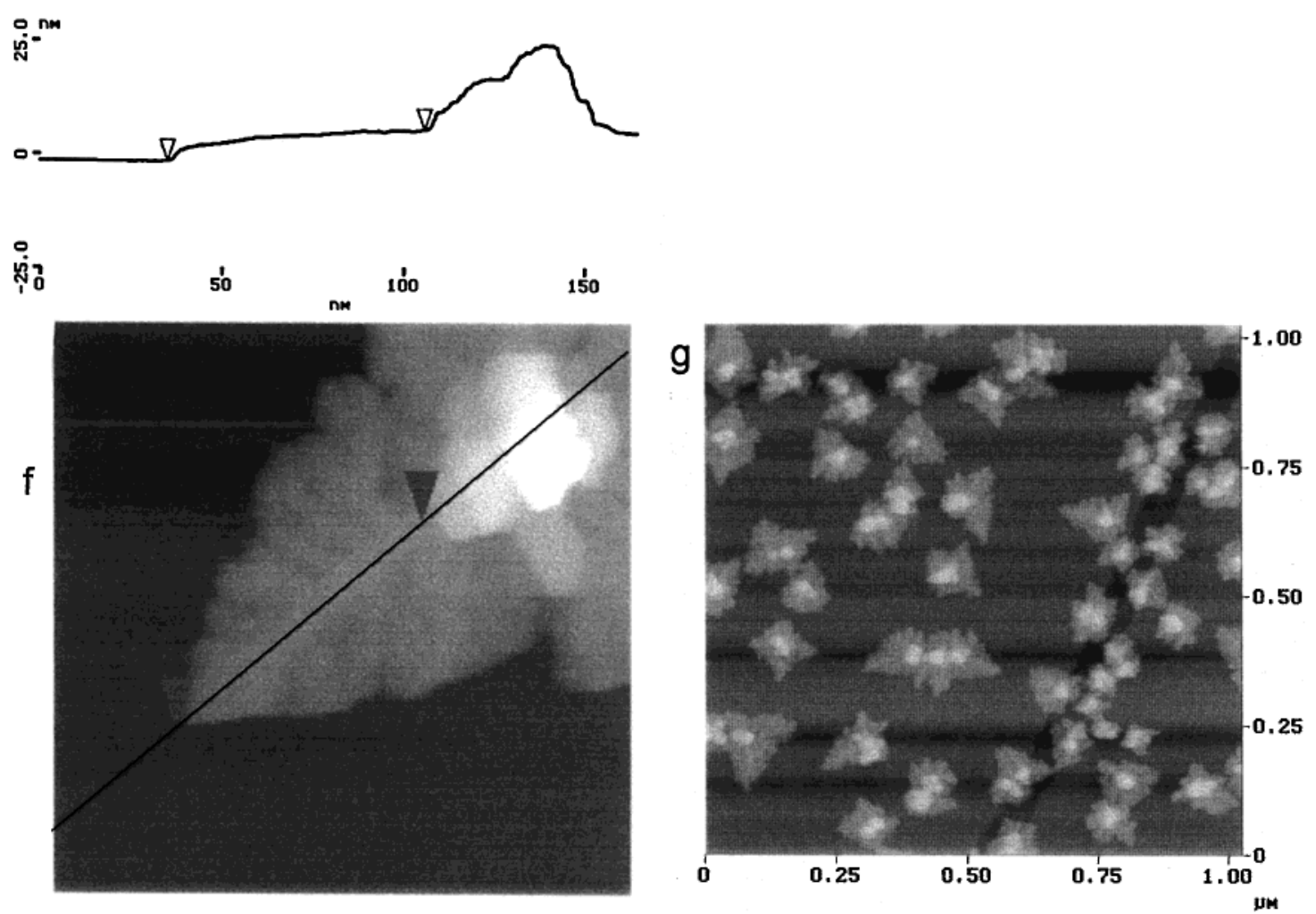

Figure 6. STM images of palladium islands produced on HOPG at $E_{\mathrm{d}}=-0.100 \mathrm{~V} ; 298 \mathrm{~K}$. (a) $1.1 \times 1.1 \mu \mathrm{m}^{2}, q_{\mathrm{d}}=1 \mathrm{mC} / \mathrm{cm}^{2}$. (b) Higherresolution STM image, $0.3 \times 0.3 \mu \mathrm{m}^{2}, q_{\mathrm{d}}=1 \mathrm{mC} / \mathrm{cm}^{2}$. (c) Image $0.2 \times 0.2 \mu \mathrm{m}^{2}$ and cross section $q_{\mathrm{d}}=1.5 \mathrm{mC} / \mathrm{cm}^{2}$. (d) Branched islands, $1.1 \times$ $1.1 \mu \mathrm{m}^{2}, q_{\mathrm{d}}=3 \mathrm{mC} / \mathrm{cm}^{2}$. (e) Branched triangular island, $0.25 \times 0.25 \mu \mathrm{m}^{2}, q_{\mathrm{d}}=3 \mathrm{mC} / \mathrm{cm}^{2}$. (f) Detail and cross section from the image depicted in Figure 6e. $(\mathrm{g})$ Branched island, $1.1 \times 1.1 \mu \mathrm{m}^{2}, q_{\mathrm{d}}=4 \mathrm{mC} / \mathrm{cm}^{2}$.

Therefore, considering eq 9 , the value of $K_{2}$ was determined from the slope of the $\ln A N_{\mathrm{o}}$ vs $\eta_{\mathrm{c}}{ }^{-2}$ linear plot (Figure $7 \mathrm{~d}$ ). Likewise, the number of atoms $\left(n^{*}\right)$ involved in the formation of the critical nucleus was calculated from the expression ${ }^{34,35}$

$$
n^{*}=2 A_{\mathrm{c}} / z e_{\mathrm{o}}\left(E_{\mathrm{d}}-0.528\right)
$$

where $e_{\mathrm{o}}=1.60 \times 10^{-19}$ abs Coulomb. Then, by combining eqs 10 and 11 , values of $n^{*}$ at different $E_{\mathrm{d}}$ result in $n^{*}=2$ for $E_{\mathrm{d}}=0.38 \mathrm{~V}$ and $n^{*}=0$ for $E_{\mathrm{d}}=-0.100 \mathrm{~V}$, in good agreement with data that have been reported for the electrocrystallization of several metals on foreign substrates. ${ }^{36}$ The decrease in $n^{*}$ with $E_{\mathrm{d}}$ is related to a decrease in the activation energy for nucleation with $\eta_{\mathrm{c}}$.

\section{Discussion}

4.1. Growth Stages of Palladium Islands on HOPG. The electrodeposition of palladium islands on HOPG occurs by a nucleation and growth process in which, depending on the applied potential, different palladium species might be involved. As usually occurs in the growth of a solid phase, ${ }^{37}$ the shape of those islands will be determined by counterbalancing effects related to the rate of metal electrodeposition and the rate of surface relaxation processes. STM images show the decoration of HOPG step edges by electrodeposited palladium clusters, which shows that the majority of active sites exists at defective sites and to a lesser extent on HOPG terraces.

Palladium island formation starts $(t=0)$ on the bare HOPG cathode $(x=0)$, but as soon as electrodeposition proceeds $(t>$ $0)$, the cathode surface consists of regions covered by palladium islands and patches of free HOPG. At this stage, the lower work function of $\mathrm{HOPG}^{38}$ as compared to palladium ${ }^{39}$ favors pal- ladium electrodeposition on palladium rather than on HOPG. ${ }^{40}$ In this case, palladium phase formation would begin prior to adsorption. At $E>0.528 \mathrm{~V}$, the initial stage should principally involve the interaction of negatively charged species with the HOPG surface, which is positively charged with respect to the solution. In fact, the potential of zero charge of the basal plane of stress-annealed pyrolitic graphite is $E_{\mathrm{pzc}}=-0.268 \mathrm{~V}$ versus $\mathrm{SCE}$ in diluted aqueous sodium fluoride and decreases to $E_{\mathrm{pzc}}$ $=-0.30 \mathrm{~V}$ versus SCE in aqueous $1 \mathrm{M}$ lithium chloride. ${ }^{38}$ This negative shift of $E_{\mathrm{pzc}}$ correlates with the possibility of anion adsorption on HOPG. Data previously reported ${ }^{21,22}$ indicate that, for $E>0.528 \mathrm{~V}$, any type of interaction of soluble palladium species and the HOPG surface is very unlikely. Furthermore, from our own experiments, no evidence that nucleation might be due to electroless deposition of palladium from the working solution was found. Therefore, palladium nucleus formation would start by the interaction of chloride ions and surface defects at positively charged HOPG as expressed by the reaction

$$
\mathrm{C}(0001)^{*}+\mathrm{Cl}^{-}(\mathrm{sol})=\mathrm{C}(0001)^{*}\left[\mathrm{Cl}^{-}\right]
$$

where the asterisk and brackets denote surface defects and adsorbed species, respectively. Subsequently, the interaction of $\left[\mathrm{Cl}^{-}\right]$with dissolved palladium species would yield $\left[\mathrm{PdCl}_{2}\right]$, a precursor for palladium nucleus formation

$$
\begin{array}{r}
\mathrm{C}(0001)^{*}\left[\mathrm{Cl}^{-}\right]+\mathrm{PdCl}_{n}{ }^{2-n}=\mathrm{C}(0001)^{*}\left[\mathrm{PdCl}_{2}\right]+ \\
(n-1) \mathrm{Cl}^{-}(x=0)
\end{array}
$$

Then, palladium nuclei would result from the discharge of soluble palladium-containing species on $\left[\mathrm{PdCl}_{2}\right]$-precursorcontaining centers by a global reaction such as 

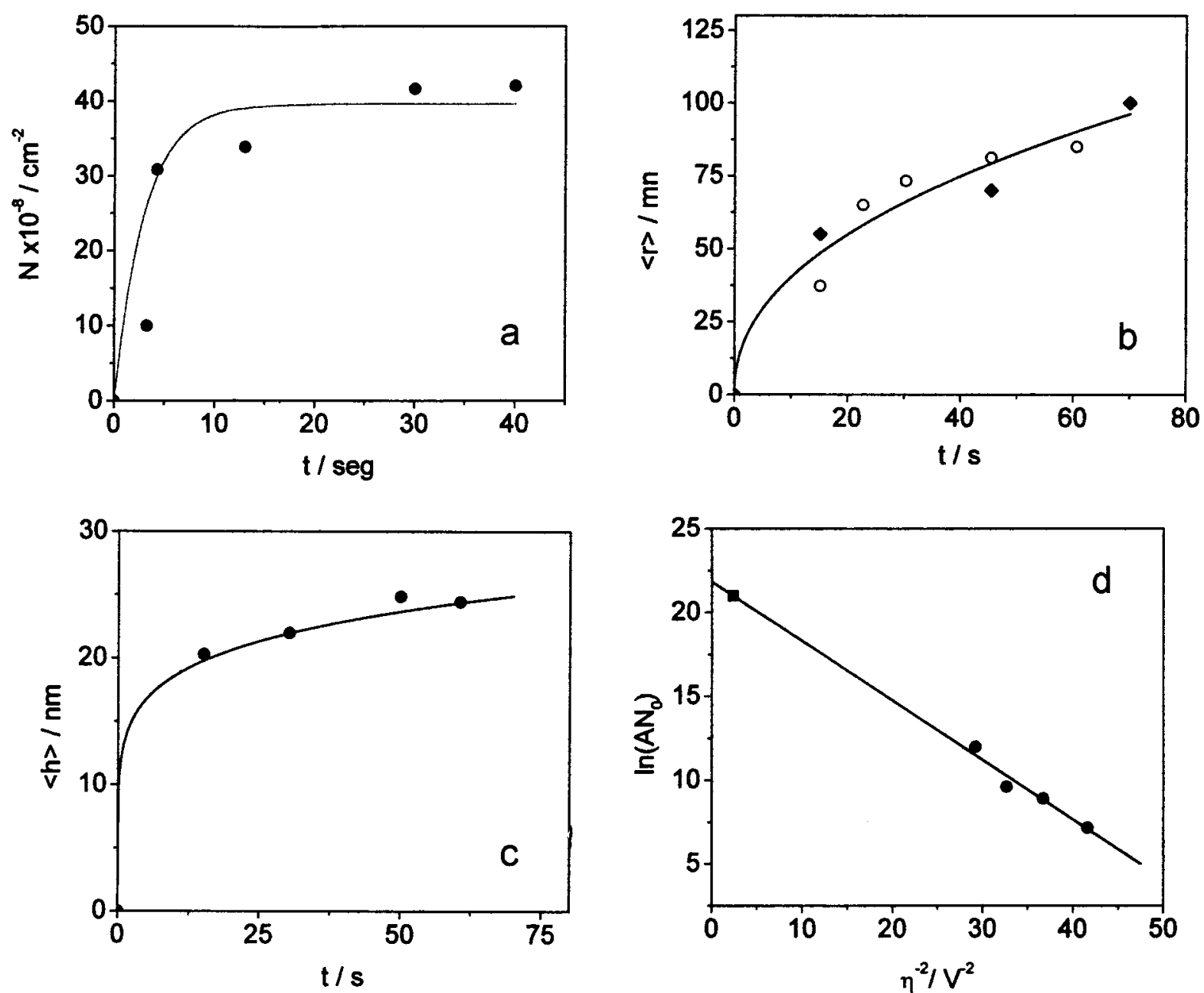

Figure 7. (a) $N$ vs $t$ plot for $E_{\mathrm{d}}=-0.100 \mathrm{~V}$. The solid line corresponds to eq 8. (b) $\langle r\rangle$ vs $t$ plot. (O) $E_{\mathrm{d}}=-0.100 \mathrm{~V}$ and $(\diamond) E_{\mathrm{d}}=0.125 \mathrm{~V}$. The solid line corresponds to the $\langle r\rangle$ vs $t^{0.4}$ plot. (c) $\langle h\rangle$ vs $t$ plot; $E_{\mathrm{d}}=-0.100 \mathrm{~V}$. The solid line corresponds to the $\langle h\rangle$ vs $t^{0.15}$ plot. (d) $\ln \left(A N_{\mathrm{o}}\right)$ vs $1 / \eta^{2}$ plot. Estimation of the number of atoms of the critical nucleus $\left(n^{*}\right)$ :

(-) data from current transients, (ם) data from the $N$ vs $t$ plot (Figure 7a).

$$
\begin{aligned}
\mathrm{C}(0001) *\left[\mathrm{PdCl}_{2}\right]+\mathrm{PdCl}_{n}{ }^{2-n}+2 \mathrm{e}^{-} & =\mathrm{C}(0001) *\left[\mathrm{Pd}_{2}\right]+ \\
& (2+n) \mathrm{Cl}^{-}(x=0)
\end{aligned}
$$

where $\left[\mathrm{Pd}_{2}\right]$ represents a critical palladium nucleus involving two atoms. Palladium nuclei continue growing by attachment of palladium adatoms produced by the discharge of soluble palladium species

$$
\begin{array}{r}
\mathrm{PdCl}_{n}{ }^{2-n}+\mathrm{C}(0001) *\left[\mathrm{Pd}_{2}\right]+2 \mathrm{e}^{-}=\mathrm{C}(0001)\left[\mathrm{Pd}_{3}\right]+ \\
n \mathrm{Cl}^{-}(x=0)
\end{array}
$$

and so on with increasing $n$.

It should be noted that the formation of the $\left[\mathrm{PdCl}_{2}\right]$ precursor has been proposed earlier from an analysis of kinetic data for palladium electrodeposition. ${ }^{21,22}$ However, the contribution of reactions 13 and 14 should depend on whether $E$, the cathodic potential, is either positive or negative with respect to $E_{\mathrm{pzc}}(\mathrm{Pd})$, the potential of zero charge of bulk palladium. Thus, for $E>$ $E_{\mathrm{pzc}}(\mathrm{Pd})$ and reversible ionic equilibrium in solution, those reactions can be represented by

$$
\begin{array}{r}
\mathrm{Pd}^{2+} \underset{+\mathrm{Cl}^{-}}{\longrightarrow} \mathrm{PdCl}^{+} \underset{+\mathrm{Cl}^{-}}{\longrightarrow} \mathrm{PdCl}_{2} \underset{+\mathrm{Cl}^{-}}{\longrightarrow} \mathrm{PdCl}_{3} \underset{+\mathrm{Cl}^{-}}{\longrightarrow} \mathrm{PdCl}_{4}{ }^{2-} \\
\downarrow \\
\mathrm{PdCl}^{+}+\mathrm{C}(0001)^{*}\left[\mathrm{Cl}^{-}\right] \rightarrow \mathrm{C}(0001)^{*}\left[\mathrm{PdCl}_{2}\right]
\end{array}
$$

and

$$
\begin{aligned}
& \mathrm{C}(0001) *\left[\mathrm{PdCl}_{2}\right]+\mathrm{PdCl}^{+}+4 \mathrm{e}^{-} \Longrightarrow \\
& \mathrm{C}(0001)^{*}\left[\mathrm{Pd}_{2}\right]+3 \mathrm{Cl}^{-}(x=0)
\end{aligned}
$$

Reaction 17 accounts for the number of atoms in the critical nucleus $n^{*}=2$ when $E>E_{\mathrm{pzc}}(\mathrm{Pd})$. Then, as reaction 17 proceeds, the local concentration of chloride ions at $x=0$ exceeds that in the bulk $(x \rightarrow \infty)$. Accordingly, the displacement of ionic equilibria at the reaction interface will favor both an increase in the concentration of those reactants with larger $\mathrm{Cl} /$ $\mathrm{Pd}$ atom number ratios and chloride ion adsorption on palladium nuclei

$$
\mathrm{C}(0001)\left[\mathrm{Pd}_{n}\right]+\mathrm{Cl}^{-}(x=0)=\mathrm{C}(0001)\left[\mathrm{Pd}_{n}\right]\left[\mathrm{Cl}^{-}\right]
$$

The above-mentioned mechanism is consistent with the retardation of palladium electrodeposition by chloride ions that has been attributed to the direct participation of $\mathrm{PdCl}_{2}$ molecules formed by the reversible dissociation of $\mathrm{PdCl}_{4}{ }^{2-} .21$ This fact accounts for the cathodic Tafel slope close to $-2.3(R T / F)$ found for current densities smaller than $j_{\mathrm{LI}}$ as indicated in section 3.1. This slope indicates that reaction 17 corresponds to an activated process that has been assigned to the activation of adsorbed $\mathrm{PdCl}_{2}$ molecules with an increase in the length of the $\mathrm{Pd}-\mathrm{Cl}$ bond. The $\left[\mathrm{PdCl}_{2}\right]$ precursor proposed above would play the 
role of an activated bridge complex involving chloride in electron-transfer reactions, as already suggested. ${ }^{41-45}$ Then, the electrochemical mechanism of electrode reactions of palladium complexes begins with an outer-sphere mechanism and then changes to an inner-sphere mechanism as has been discussed elsewhere. $^{22}$

On the other hand, for $E<E_{\mathrm{pzc}}(\mathrm{Pd}) \approx 0.026 \mathrm{~V}$ versus $\mathrm{SCE}$, the electrochemical reaction is under mass transport control, the concentration of chloride ions at $x=0$ tends to zero, and the formation of $\mathrm{C}^{*}(0001)\left[\mathrm{Cl}^{-}\right]$adsorbate through reaction 12 is largely impeded. Accordingly, the formation of the $\left[\mathrm{PdCl}_{2}\right]$ precursor will be hindered, and the global discharge reaction of soluble palladium species will proceed as a bulk random process at $\mathrm{C}(0001)^{*}$ centers without the formation of critical nuclei

$$
\begin{array}{r}
\mathrm{C}(0001)^{*}+n^{\prime} \mathrm{PdCl}_{n}^{2-n}+2 n^{\prime} \mathrm{e}^{-}=\mathrm{C}(0001)^{*}\left[\mathrm{Pd}_{n^{\prime}}\right]+ \\
n^{\prime}(2+n) \mathrm{Cl}^{-}(x=0)
\end{array}
$$

and

$$
\mathrm{Cl}^{-}(x=0) \Longrightarrow \mathrm{Cl}^{-}(x=\infty)
$$

Therefore, $n_{*} \rightarrow 0$, as is observed for high values of $\eta_{\mathrm{c}}$. The decrease in the estimated values of $n^{*}$ from a finite value to zero as $\eta_{\mathrm{c}}$ is increased should be related to the influence of the kinetics of the cathodic reaction in terms of $E_{\mathrm{pzc}}(\mathrm{Pd})$ as well as the decrease in the activation energy for nucleation with $\eta_{\mathrm{c}}$. The same behavior of $n *$ has been observed in both the classical and atomistic treatment of the experimental results for the electrodeposition of $\mathrm{Ag}^{+}$on platinum, $\mathrm{Pt}(100)$ and $\mathrm{Pt}(111), \mathrm{Hg}^{2+}$ on platinum, and $\mathrm{Cu}^{2+}$ on both platinum and palladium. ${ }^{36}$

4.2. Island Growth and Aspect Ratio. Island growth under a quasi-steady convective-diffusion process implies the formation of a depletion region for reactants around palladium islands whose average thickness is smaller than the distance between them. It has been reported ${ }^{46}$ that, for nuclei growing on a solid substrate at the distance $2 r$, where $r$ is the nucleus radius, the concentration of the electroactive species is close to one-half its value in the bulk. This is consistent with the fact that electroactive species are preferentially discharged on palladium islands rather than on HOPG, in agreement with the lower work function of HOPG as compared to palladium. ${ }^{40}$ Therefore, as the distance separating palladium islands becomes small, the overlapping of diffusion zones built up around growing nuclei takes place. As nucleation and growth proceeds, the free HOPG/ palladium island surface area ratio decreases, and consequently, the efficiency of palladium reactant discharge on palladium islands increases.

The dependence of palladium island shape on both $\eta_{\mathrm{c}}$ and solution composition in the interfacial region indicates that the global reactions $12-19$ are coupled to surface relaxation processes, which are mainly responsible for the aspect ratio of electrodeposits.

For the range $-0.10 \leq E \leq 0.15 \mathrm{~V}$, the average radius of islands is always greater than the radius calculated for a semispherical island involving the same amount of deposited palladium. This is reflected in the low $h / r$ ratio found for these islands and indicates that relatively fast surface atom relaxation takes place during island growth in this potential region. Further, considering that this type of relaxation occurs at a temperature much lower than one-half the value of the melting temperature of palladium, it seems reasonable to explain the surface relaxation process by adatom surface diffusion. Therefore, surface diffusion has a key role in determining the island shape in the whole potential range of our experiments.

For palladium as well as for other fcc(111) surfaces, there are two types of step edges, the so-called A and B types. The height of the activation energy barrier for interterrace adatom surface diffusion for A-type steps is greater than that for B-type steps. For palladium, theoretical calculations have shown that the energy barrier at a B-type step will be low, whereas, at an A-type step, it will be higher than the energy barrier for intraterrace adatom surface diffusion. ${ }^{48}$ This situation favors 2D anisotropic growth leading to triangular islands. ${ }^{31,32}$ Conversely, adsorbed species such as chloride ions decrease the height of the activation energy barriers for surface diffusion as well as the height difference of the activation energy barriers for Aand B-type steps. Therefore, this fact should favor the symmetric $2 \mathrm{D}$ growth of the island. A mechanism of this type including surface relaxation has recently been discussed for gold island electroformation on HOPG under both above-mentioned situations. $^{5,6}$

4.2.1. Negatively Charged Electrode Surface. STM images of branched 2D palladium islands formed at $-0.1 \mathrm{~V}$ show a change in the growth mode when the island exceeds the core size. Thus, the central quasi-spherical core turns into a dense radial-type island that approaches a quasi-2D pattern. We also note a preferential trigonal symmetry of islands that is consistent with the development of $\operatorname{Pd}(111)$ faces, in agreement with the predictions that the interterrace displacement of palladium adatoms through B-type steps occurs without significant restrictions leading to the growth of $2 \mathrm{D}$ patterns with a trigonal geometry. The contribution of a small flux of palladium adatoms to the island edges from the discharge of reactants on HOPG could be associated with local instabilities that would contribute to branch triggering at island edges.

From the atomistic standpoint two diffusion processes at crystal edges can be distinguished, depending on whether an adatom starts from a site that is laterally two-fold (edge diffusion) or one-fold (corner diffusion) coordinated to the crystal edge. ${ }^{49}$ Dendritic patterns with trigonal symmetry on hexagonal surfaces have been generated, introducing anisotropic corner surface atom diffusion, whereas edge diffusion leads mainly to branch thickening. The anisotropy of corner surface atom diffusion caused by the presence of A- and B-type steps stabilizes tip growth and leads to branched patterns similar to those found for our palladium electrodeposits. The time dependence of the island radius, island height, and island slope is consistent with this picture (Figure 7b,c). Accordingly, as $t$ increases, the island slope, $s=\langle h\rangle /\langle r\rangle$, decreases as $s \propto t^{-1 / 4}$. This exponent is consistent with $n=0.4$ and $m=0.15$ and means that atoms landing on island tops move downward through terraces to island edges via B-type steps. Monte Carlo simulations for a growth process with low energy barriers at step edges show that, as $s$ decreases, $n$ tends to $0.4 .{ }^{49} \mathrm{~A}$ comparable situation, i.e., $n=0.4$ and decreasing $s$, has been observed for the growth of germaniun on $\mathrm{Ge}(001)$, a surface that exhibits small step energy barriers. ${ }^{50}$ Therefore, for branched palladium islands, the absence of significant deviations from a perfect 2D island is justified (Figure 8a). The small deviation from a $2 \mathrm{D}$ pattern could be related to the misfit of the HOPG and palladium lattices - their lattice constants are $a=142 \mathrm{pm}$ and $a=256 \mathrm{pm}$, respectively-that also contributes to their aspect ratio, as has recently been reported for gold clusters produced on HOPG from the vapor phase. ${ }^{47}$ It should be noted that, for barrierless surface diffusion, the value $n=0.5$ is expected. ${ }^{37}$ Otherwise, for dendritic gold islands on HOPG, the 


\section{Ln-}
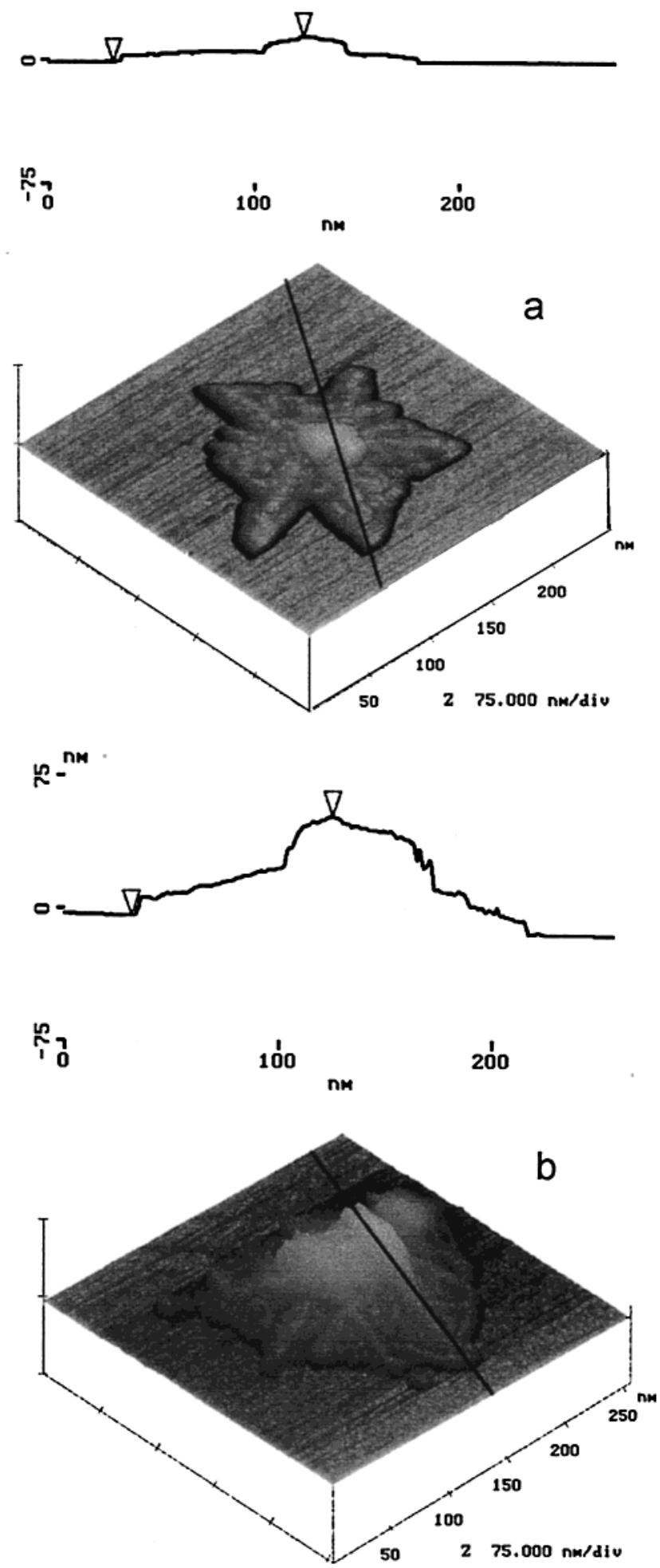

Figure 8. Comparison of the STM 3D morphology of (a) palladium and (b) gold islands electrodeposited on HOPG at $E_{\mathrm{d}}=-0.100 \mathrm{~V}$ and $q_{\mathrm{d}}=2 \mathrm{mC} \mathrm{cm}^{-2}$.

values $n=0.25$ and $m=0.25$ have been reported, so that $s$ remains constant during growth. These figures indicate the presence of significant step energy barriers for gold atom interterrace surface diffusion. ${ }^{5,6}$ Calculations have shown that, even for B-type steps, the energy barrier for adatom surface diffusion is higher than that for intraterrace surface diffusion. ${ }^{48}$
In fact, dendritic gold islands exhibit a significant deviation from perfect 2D islands, i.e., 3D growth is not negligible (Figure 8b). Finally, it should be noted that anisotropic palladium islands are grown at $E_{\mathrm{d}}<E_{\mathrm{pzc}}(\mathrm{Pd})=0.026 \mathrm{~V}$. In this case, a negligible influence of adsorbed chloride ions on the surface mobility of palladium should be expected. Therefore, the shape of palladium islands grown electrochemically at $E_{\mathrm{d}}<E_{\mathrm{pzc}}(\mathrm{Pd})$ is consistent with the predictions of theoretical growth models for palladium deposits from the vapor phase in which there is no influence of adsorbed species from the environment. ${ }^{32}$ From the standpoint of phase formation, the two deposition processes behave almost alike.

4.2.2. Positively Charged Electrode Surface. For $t \rightarrow 0, E>$ $E_{\mathrm{pzc}}(\mathrm{HOPG})$, and $E>E_{\mathrm{pzc}}(\mathrm{Pd})$, the attachment of palladium adatoms to nuclei/clusters/islands occurs in the presence of a relatively large concentration of chloride ions at $x=0$ interacting with both the HOPG and palladium cluster surfaces. In this case, no significant changes in the time dependences of $\langle r\rangle,\langle h\rangle$, and $s$ are observed with respect to those measured for branched islands. However, adsorbed chloride assists the isotropic interterrace surface diffusion of palladium adatoms so that initially formed clusters acquire a compact round disk shape. In fact, as $E \rightarrow E_{\mathrm{pzc}}(\mathrm{Pd})$, instabilities at island edges can be observed, although they cannot give rise to stable branches because of the enhancement of palladium adatom surface diffusion promoted by chloride ions, which tends to eliminate those instabilities leading to compact rounded islands. Therefore, we propose that the enhancement of adatom edge diffusion at palladium islands grown at $E_{\mathrm{d}} \approx 0.125 \mathrm{~V}$ is promoted by chloride ion adsorption resulting from reactions 18 and 19 on the positively charged palladium surface. Hence, the island shape deviates from vapor-phase expectations because of chloride anion adsorption. It is well-known that chloride ion adsorption on metals enhances the surface diffusion of metal adatoms by weakening the metal-metal bonds. ${ }^{51}$

4.3. Surface Atom Relaxation. As surface diffusion plays a key role in determining the average aspect ratio of palladium islands, we attempted to estimate the average surface selfdiffusion coefficient, $D_{\mathrm{s}}$, of various surface species involved in the global electrodeposition process and to discriminate their likely structure. For this purpose, the equation proposed by Gjostein to systematize surface diffusion coefficients measured in vacuum or in the presence of a gas, modified by Rhead to include the presence of contaminants, was used. ${ }^{52,53}$

Results point out that chloride ions at the reaction interface are responsible for the surface mobility enhancement of palladium species on the growing phase for $E>E_{\mathrm{pzc}}$. Then, let us consider that surface diffusing species are either bare palladium atoms or $\left[\mathrm{PdCl}_{2}\right]$ surface species with a stoichiometry similar to that of the reaction intermediate that has been proposed for the electrochemical discharge of $\mathrm{PdCl}_{n}{ }^{(n-2)-}$ species in aqueous environment. ${ }^{21,22}$ The value of $D_{\mathrm{s}}$ can be estimated from the Gjostein-Rhead equation, ${ }^{52,53}$ i.e.

$$
\begin{aligned}
D_{\mathrm{s}}=740 \times 10^{-4} \exp (- & \left.30 T_{\mathrm{m}} / R T\right)+ \\
& 0.014 \times 10^{-4} \exp \left(-13 T_{\mathrm{m}} / R T\right)
\end{aligned}
$$

where $T=298 \mathrm{~K}, T_{\mathrm{m}}$ is the melting point of the substance, and $R=1.987 \mathrm{cal} /(\mathrm{mol} \mathrm{K})$. For palladium, $T_{\mathrm{m}}=1827 \mathrm{~K}$, and for $\mathrm{PdCl}_{2}, T_{\mathrm{m}} \approx 773 \mathrm{~K}$. Then, eq 20 results in $D_{\mathrm{s}}=6.1 \times 10^{-14}$ $\mathrm{cm}^{2} / \mathrm{s}$ for $\mathrm{PdCl}_{2}$, and $D_{\mathrm{s}}=5.7 \times 10^{-24} \mathrm{~cm}^{2} / \mathrm{s}$ for palladium. Despite the gap between surface processes in a vacuum and in condensed interfaces, eq 20 leads to an increase in the value of $D_{\mathrm{s}}$ for $\mathrm{PdCl}_{2}$, following the same tendency already reported for 
the mobility of gold atoms on gold surfaces in chloridecontaining aqueous environments at $298 \mathrm{~K} .{ }^{54}$ In this case, the surface diffusion of gold atoms is also probably assisted by the formation of a complex surface species. ${ }^{55}$ Likewise, the above value of $D_{\mathrm{s}}$ is of the same order as that recently found for the surface diffusion of disk-shaped aggregates of cadmium sulfide nanocrystals on HOPG surfaces at $50-100{ }^{\circ} \mathrm{C} .{ }^{56}$ For such a high value of $D_{\mathrm{s}}$, the average travelling rate of $\left[\mathrm{PdCl}_{2}\right]$ species on palladium surface would be about $1 \mathrm{~nm} / \mathrm{s}$. This figure is consistent with surface relaxation contributing to the formation of rounded islands for $E>0.5 \mathrm{~V}$, i.e., under these conditions, isotropic radial growth is favored.

\section{Conclusions}

At low cathodic overpotentials, the electroformation of palladium islands on $\mathrm{HOPG}$ proceeds as an activated process with the participation of a $\left[\mathrm{PdCl}_{2}\right]$ surface intermediate, whereas at high cathodic overpotentials, it approaches quasi-steady convective-diffusion kinetics.

The analysis of potentiostatic current transients recorded at intermediate cathodic overpotentials shows that the cathodic reaction proceeds by progressive nucleation under diffusion control. Current transient data allowed us to evaluate the diffusion coefficient of reactants in solution, the rate of nucleation, and the number density of nuclei. The number of atoms in the critical nucleus decreases from 2 to 0 as the cathodic overpotential is increased.

The mechanism for palladium island formation and the aspect ratio of islands depend on whether the cathodic potential is above or below the potential of zero charge of bulk palladium.

For $E<E_{\mathrm{pzc}}(\mathrm{Pd})$, palladium islands exhibit a branched quasi$2 \mathrm{D}$ growth. This growth mode can be explained in terms of the difference in the activation energy barriers for interterrace surface diffusion through A- and B-type step edges at a hexagonal lattice and the low step energy barrier for B-type steps at the $\operatorname{Pd}(111)$ surface.

For $E=0.125 \mathrm{~V}>E_{\mathrm{pzc}}(\mathrm{Pd})$, the adsorption of chloride ions enhances surface diffusion and favors compact $2 \mathrm{D}$ quasiisotropic island formation. The mobile surface species can be related to a $\left[\mathrm{PdCl}_{2}\right]$ stoichiometry that is produced as an intermediate in the cathodic process. Its average surface diffusion coefficient was estimated from the Gjostein-Rhead equation. There is a reasonable correlation between the kinetics and mechanism of palladium electrodeposition, its dependence on the solution composition, and the aspect ratio of palladium islands produced on HOPG.

Acknowledgment. This work was financially supported by Projects IN94-05553 and PI-1999/128 from Gobierno Canario (Spain), PIP 0897/98 and PIP 4376 from CONICET (Argentina), and PICT 99-5030 and PICT 03251/98 from Agencia Nacional de Promoción Científica y Tecnológica (Argentina). R.C.S. thanks the Dirección General de Investigación Científica y Enseñanza Superior (Spain) for financial support.

\section{References and Notes}

(1) Godrèche, C., Ed. Solids far from Equilibrium; Cambridge University Press, New York, 1991. Bunde, A, Havlin, S. Fractals and Disordered Systems; 2nd ed.; Springer: Frankfurt, Germany, 1996.

(2) Hurle, D. T. J. Handbook of Crystal Growth I. Fundamentals; Elsevier: Amsterdam, 1993; Part A. Thermodynamics and Kinetics.

(3) Hurle, D. T. J. Handbook of Crystal Growth I. Fundamentals; Elsevier: Amsterdam, 1993; Part B. Transport and Stability.
(4) Avnir, D., Ed. The Fractal Approach to Heterogeneous Catalysis; John Wiley \& Sons: New York, 1989.

(5) Martin, H.; Carro, P.; Hernández Creus, A.; González, S.; Salvarezza, R. C.; Arvia, A. J. Langmuir 1997, 13, 100.

(6) Martin, H.; Carro, P.; Hernández Creus, A.; González, S.; Salvarezza, R. C.; Arvia, A. J. J. Phys. Chem. 1999, 103, 3900.

(7) Martin, H.; Carro, P.; Hernández Creus, A.; Salvarezza, R. C.; Arvia, A. J. Phys. Rev. B 1998, 58, 9666. Schilardi, P. L., Azzaroni, O.; Salvarezza, R. C.; Arvia, A. J. Phys. Rev. B 1999, 59, 4638.

(8) Li, Y.; De Pristo, E. Surf. Sci. 1996, 351, 189.

(9) Schwarzenbach, G. Helv. Chem. Acta 1949, 32, 839

(10) Archer, M. D.; Spiro, M. J. Chem. Soc. A 1970, 68.

(11) Hirschenhofer, R. R.; Stauffer, D. B.; Engleman, R. R.; Klett, M. G. Fuel Cell Handbook, 4th ed.; U.S. Department of Energy, Office of Fossil Energy, Federal Energy Technology Center: Morgantown, NY, 1998.

(12) Heinz, K.; Guttmann, M.; Beyer, L. J. Electroanal. Chem. 1999, 462, 174.

(13) Rusanova, M. Y.; Tsirlina, G. A.; Petrii, O. A.; Safonova, T. Y.; Vasiliev, S. Y. Russ. J. Electrochem. 2000, 36, 457 and references therein.

(14) Tsirlina, G. A.; Baronov, S. B.; Spiridonov, F. M.; Rusanova, M.

Y.; Safonova, T. Y.; Petrii, O. A. Russ. J. Electrochem. 2000, 36, 1179.

(15) Spiro, M.; De Jesús, D. M. Langmuir 2000, 16, 2464, 4896.

(16) Laureyn, W.; Van Gerwen, P.; Suls, J.; Jacobs, P.; Maes, G. Electroanalysis 2001, 13, 204.

(17) Memmel, N. Surf. Sci. Rep. 1998, 32, 91.

(18) Henry, C. R. Appl. Surf. Sci. 2000, 164, 252.

(19) Li, F.; Wang, E.; Dong, D. J. Electroanal. Chem. 1997, 422, 27.

(20) Che, M.; Benett, C. O. Adv. Catal. 1997, 36, 27.

(21) Kravtsov, V. I.; Zelinskii, M. I. Elektrokhimiya 1966, 2, 1138.

(22) Kravtsov, V. I. J. Electroanal. Chem. 1976, 69, 125; Russ. J. Electrochem. 2000, 36, 1365

(23) Standard Potentials in Aqueous Solution; Bard, A. J., Parsons, R., Jordan, J., Eds.; IUPAC and Marcel Dekker: New York, 1985.

(24) Smith, R. M.; Martell, A. R. Critical Stability Constants; Plenum Press: New York, 1976; Vol. 4, p 107.

(25) Levich, V. G. Physicochemical Hydrodynamics; Prentice-Hall: Englewood Cliffs, NJ, 1962.

(26) Miranda-Hernández, M.; González, I.; Batina, N. J. Phys. Chem. $B$ 2001, 105, 4214 .

(27) Salvarezza, R. C.; Montemayor, C.; Fatas, E.; Arvia, A. J. J. Electroanal. Chem. 1991, 313, 291.

(28) Millet, P.; Srour, M.; Fauré, R.; Durand, R. Electrochem. Commun. 2001, 3, 478

(29) Andreasen, G.; Visintin, A.; Salvarezza, R. C.; Triaca, W. E.; Arvia, A. J. Langmuir 1999, 7, 1.

(30) Thomas, P. J.; Kulkarni, G. U.; Rao, C. N. R. J. Phys. Chem. B 2001, 105, 2515.

(31) Kojima, I.; Srivastava, A. K.; Kurahashi, M. Jpn. J. Appl. Phys. 1991, 30, 1852 .

(32) Bonet, M.; Boschung, E.; Hayoz, J.; Pillo, T.; Dietler, G. Aebi, P. Surf. Sci. 2001, 47317.

(33) Scharifker, B.; Hills, G. Electrochim. Acta 1983, 288, 79

(34) Scharifker, B.; Mostany, J. J. Electroanal. Chem. 1984, 177, 13.

(35) Budevski, E. B. In Comprenhensive Treatise of Electrochemistry; Conway, B. E., Bockris, J. O’M., Yeager, E., Khan, S. U. M., White, R., Eds.; Plenum Press: New York, 1983; Vol. 7.

(36) Budevski, E.; Staikov, G.; Lorenz, W. J. Electrochemical Phase Formation and Growth; VCH: Weinheim, Germany, 1996.

(37) Barabási, A. L.; Stanley, H. E. Fractal Concepts in Surface Growth; Cambridge Universy Press: New York, 1995.

(38) Randin, J. P. In Encyclopedia of Electrochemistry of the Elements; Bard, A. J. Ed.; Marcel Dekker: New York, 1976; Vol. VIII-1 Carbon, p 37.

(39) Frumkin, A. N.; Petrii, O. A. Electrochim. Acta 1975, 20, 347.

(40) Lubert, K.-H.; Guttmann, M.; Beyer, L.; Kalcher, K. Electrochem Commun. 2001, 3, 106.

(41) Zener, C. Phys. Rev. 1951, 82, 493.

(42) Libby, W. F. J. Phys. Chem. 1952, 56, 39.

(43) Lyons, W. H., Jr. J. Electrochem. Soc. 1954, 101, 376.

(44) Taube, H.; Myers, H. J. Am. Chem. Soc. 1954, 76, 2103.

(45) Gerischer, H. Chem.-Ing.-Techn. 1964, 36, 666

(46) Fletcher, S. J. Chem. Soc., Faraday Trans. 1983, 79, 467.

(47) Blum, B.; Salvarezza, R. C.; Arvia, A. J. J. Vac. Sci. Technol. B 1999, 17, 2431 .

(48) Brune, H.; Roder, H.; Bromann, K.; Kern, K.; Jacobsen, J.; Norskov, J. Surf. Sci. 1996, 76, L115.

(49) Smilauer, P.; Vvendenski, D. D. Phys. Rev. B 1995, 52, 14263. 8071 . 
(51) García, M. P.; Gómez, M. M.; Salvarezza, R. C.; Arvia, A. J. J. Electroanal. Chem. 1994, 375, 2291.

(52) Gjostein, N. A. In Surfaces and Interfaces I; Burke, J. J., Reed, N. L., Weiss, V., Eds.; Syracuse University Press: Syracuse, NY, 1967; p 271.

(53) Rhead, G. E. Surf. Sci. 1969, 15, 353; 1970, 22, 223.
(54) Trevor, D. J.; Chidsey, C. E. D.; Loiacono, D. N. Phys. Rev. Lett. 1989, 62, 929.

(55) Galvele, J. R. In Modern Aspects of Electrochemistry; White, R. E., Bockris, J. O’M., Conway, B. E., Eds.; Plenum Press: New York, 1995; Number 27, p 233 and references therein.

(56) Ge, G.; Brus, L. E. Nano Lett. 2001, 1, 219. 